\title{
Atmospheric blocking events in the North Atlantic: trends and links to climate anomalies and teleconnections
}

\author{
Hussein Wazneh ${ }^{1,2,3}$ [ Philippe Gachon ${ }^{1,3} \cdot$ René Laprise $^{2,3} \cdot$ Anne de Vernal $^{2,3} \cdot$ Bruno Tremblay $^{4}$
}

Received: 10 July 2020 / Accepted: 10 December 2020 / Published online: 5 January 2021

(C) The Author(s) 2021, corrected publication 2021

\begin{abstract}
Atmospheric blockings are generally associated with large-scale high-pressure systems that interrupt west-to-east atmospheric flow in mid and high latitudes. Blockings cause several days of quasi-stationary weather conditions, and therefore can result in monthly or seasonal climate anomalies and extreme weather events on the affected regions. In this paper, the long-term coupled CERA-20C reanalysis data from 1901 to 2010 are used to evaluate the links between blocking events over the North Atlantic north of $35^{\circ} \mathrm{N}$, and atmospheric and oceanic modes of climate variability on decadal time scales. This study indicates more frequent and longer lasting blocking events than previous studies using other reanalyses products. A strong relationship was found between North Atlantic blocking events and North Atlantic Oscillation (NAO), Atlantic Multidecadal Oscillation (AMO) and Baffin Island-West Atlantic (BWA) indices, in fall, winter and spring. More blocking events occur during the negative phases of the NAO index and positive phases of the BWA mode. In some situations, the BWA patterns provide clearer links with the North Atlantic blocking occurrence than with the NAO alone. The correlation between the synchronous occurrences of AMO and blocking is generally weak, although it does increase for a lag of about 6-10 years. Convergent cross mapping (CCM) furthermore demonstrates a significant two-way causal effect between blocking occurrences and the NAO and BWA indices. Finally, while we find no significant trends in blocking frequencies over the last 110 years in the Northern Hemisphere, these events become longer lasting in summer and fall, and more intense in spring in the North Atlantic.
\end{abstract}

Keywords Northern hemisphere · North Atlantic · Atmospheric blocking · Teleconnection indices · Climate variables · Convergent cross mapping

\section{Introduction}

Atmospheric blocking is a term used by meteorologists referring to weather situations in which the normal zonal flow is temporarily suppressed in a sector by strong persistent meridional type flow (e.g., Rex 1950; Tibaldi and

Hussein Wazneh

wazneh.hussein@uqam.ca

1 Department of Geography, University of Québec at Montréal (UQAM), Québec, Canada

2 Department of Earth and Atmospheric Sciences, University of Québec at Montréal (UQAM), Québec, Canada

3 ESCER (Étude et Simulation du Climat à l'Échelle Régionale) Centre, University of Québec at Montréal (UQAM), Québec, Canada

4 Department of Atmospheric and Oceanic Sciences, McGill University, Québec, Canada
Molteni 1990; Treidl et al. 1981). Blocking events are generally associated with persistent high-pressure systems that interrupt the prevailing westerly winds of middle and high latitudes, thus hindering the normal eastward propagation of extratropical weather systems (Ionita et al. 2016; Pfahl et al. 2015; Schwierz et al. 2004; Stocker 2014). Persistent episodes of extreme weather in the Northern Hemisphere (NH) have been shown to be associated with high-amplitude quasi-stationary atmospheric Rossby waves (Mann et al. 2017), disrupting the passage of the transient waves, a condition known as blocking event (Nakamura and Huang 2018; Woollings et al. 2010). In the NH, blocking events are frequent at the exit zones of the jet stream, as for example over the northeastern North Atlantic and the eastern Pacific regions (see Barriopedro et al. 2006; Nakamura and Huang 2018). The frequency of blocking events varies seasonally with a maximum in winter-spring, and a minimum in summer-fall (Parsons et al. 2016; Trenberth and Mo 1985; 
Wiedenmann et al. 2002). Over the North Atlantic and North Pacific, most of atmospheric blocking events occur during winter. Continental blocking events, on the other hand, are more frequent during summer (Barriopedro et al. 2010; Tyrlis and Hoskins 2008). Blocking events are less frequent in the Southern Hemisphere than in the $\mathrm{NH}$, and when they appear, they are concentrated over the southeast Pacific and the Indian Oceans.

Once established, a blocking pattern can persist several days to several weeks before decaying rather suddenly, followed by a return to westerly flow and transient waves (Knox and Hay 1985; Wiedenmann et al. 2002). Blocking events are quasi-static phenomena that have a significant impact on surface weather conditions (Scherrer et al. 2006) and are a significant component of extratropical intra-seasonal variability, thus causing climate anomalies over middle and high latitudes (Carrera et al. 2004). Blocking events deflect the eastward-travelling extratropical cyclones in the North Atlantic or North Pacific toward a more pronounced north or south direction, thus modifying substantially the zonal atmospheric flow. Their occurrences can affect the precipitation distribution and may result in drought or flood events in summer (Lupo et al. 2012). They can also produce strong advection of polar air on their eastern flank, inducing extreme cold spells in winter, as is taking place across Europe (Cattiaux et al. 2013). In eastern North America, intra-seasonal cold spells are characterized by a quasi-stationary cyclone over the Great Lakes and a dipole in the Pacific sector, with anticyclonic circulation around the Bering Strait (Messori et al. 2016), and a southward extension or unusual propagation of the surface anticyclone from Canada (Grotjahn et al. 2016; Walsh et al. 2001). The North American extreme temperature events during winter are modulated by the Pacific-North American (PNA) pattern, North Atlantic or Arctic Oscillation (NAO or AO, respectively), and blocking patterns (Cellitti et al. 2006; Grotjahn et al. 2016; Guirguis et al. 2011; Walsh et al. 2001).

Low- and high-frequency atmospheric circulation variability is associated with cold/warm temperature on synoptic (2-5 days), intra-seasonal, seasonal and interannual time scales. Teleconnection indices, also called modes of atmospheric or oceanic variability (see a general overview in Wang et al. 2004), have been identified as the source of recurring and persistent, large-scale patterns of pressure and circulation anomalies that cover large geographical areas (Barnston and Livezey 1987). Those indices are known as modes of low-frequency variability. A well-known example of these modes is the periodic NAO (Hurrell 1995), defined as the difference of normalized mean sea level pressure over eastern North Atlantic between Lisbon $\left(38^{\circ} 42^{\prime} 49.75^{\prime \prime} \mathrm{N}\right.$, $\left.9^{\circ} 8^{\prime} 21.79^{\prime \prime} \mathrm{W}\right)$ Portugal and Reykjavik ( $64^{\circ} 08^{\prime} 17^{\prime \prime} \mathrm{N}, 21^{\circ}$ $55^{\prime} 43^{\prime \prime} \mathrm{W}$ ) Iceland (Moore et al. 2013). This mode is generally associated with changes in the frequency and trajectory of extratropical cyclones circulating in the North Atlantic Ocean (Hurrel and van Loon 1997). Several studies indicate that the interannual variability of atmospheric circulation patterns in the NH is affected by the NAO (e.g., Trigo et al. 2002). Different views exist concerning the dynamics behind NAO time scales, as NAO has been interpreted as a stochastic process with a relatively short time scale originating from synoptic-scale waves (Benedict et al. 2004; Feldstein 2000). Other studies point out a significant influence of blocking upon the NAO pattern in the Euro-Atlantic sector, whereas long-lasting blocks are associated with the development of negative NAO index values (Croci-Maspoli et al. 2007). Other studies point also to an influence of the Atlantic Ocean and much longer intrinsic time scales (Rodwell et al. 1999).

Shabbar et al. (1997) introduced the Baffin Island-West Atlantic (BWA) index, defined as the difference of 500$\mathrm{hPa}$ geopotential height between Baffin Island $\left(52^{\circ} \mathrm{N}, 60^{\circ}\right.$ $\mathrm{W})$ and the western North Atlantic $\left(30^{\circ} \mathrm{N}, 60^{\circ} \mathrm{W}\right)$. These authors argue that the BWA explains a larger fraction of the temperature variability in northeastern North America when compared with the NAO. Coulibaly et al. (2000) have also found that the BWA provides better forecast for annual runoff in the northern Québec-Labrador (i.e., over northeastern Canada) than the NAO.

The Atlantic Multidecadal Oscillation (AMO) is another important mode of low-frequency multi-decadal variability characterizing the North Atlantic Ocean. It is based on seasurface temperature (SST) anomalies in the North Atlantic between $0^{\circ}$ and $70^{\circ} \mathrm{N}$ (Enfield et al. 2001) and varies with a period of 60-80 years (Trenberth and Shea 2006). Several studies have shown that SST variations related to the AMO drive climate and precipitation patterns over North America (Enfield et al. 2001; Knight et al. 2006), droughts in the Sahel region of Africa (Folland et al. 1986), variability in northeast Brazilian rainfall (Folland et al. 2001), as well as tropical and Atlantic hurricane frequency and intensity (Trenberth and Shea 2006). The AMO is also believed to influence regional to hemispheric-scale climate trends as far away as the Tibetan Plateau and India, possibly through changes in the interhemispheric redistribution of heat (Feng and $\mathrm{Hu}$ 2008). Atlantic warm SST anomalies of AMO could initiate anomalous cooling in the equatorial central-eastern Pacific through atmospheric teleconnections as the Atlantic Ocean plays a determinant role on the multidecadal SST variability at global scale (Yang et al. 2020).

There is a limited understanding of the time scale and dynamics of the processes at the origin of low- and highfrequency modes of variability (Grotjahn et al. 2016). Hence, the relationships between teleconnection indices and the blocking events are not yet fully understood, notably for the onset of blocking events in relation with both atmospheric (Nakamura and Huang 2018) and oceanic variability or anomalies. A number of studies have 
examined the correlation between blocking events and some atmospheric climate variables and modes of variability. For example, Barriopedro et al. (2006) analyzed the link between NH blocking events and NAO index using a 55-year (1948-2002) data set. They found that more blocking events occur in the negative phase of NAO, also noted by Nakamura and Huang (2018). Wiedenmann et al. (2002) studied the link between the blocking events and the El Niño/Southern Oscillation (ENSO) index using a 30-year data series. They found that Northern (Southern) Hemisphere blocking events were stronger and more frequent during La Niña (El Niño) years. Fei et al. (2002) used composite analysis to show the possible relationships between the variability of blocking and SSTs. García-Herrera and Barriopedro (2006) used a 31-year data set to show the relationship between the $\mathrm{NH}$ snow cover and regional blocking patterns. They found that snow cover exerts an important influence on regional atmospheric blocking, which in turn modulates snow cover extent at subcontinental scales. Photiadou et al. (2014) have shown that the NAO and atmospheric blocking influence more the magnitude and duration of intense warm anomalies over Europe than ENSO events. Francis and Vavrus (2012) argue that polar amplification associated with global warming leads to a reduced temperature gradient between the equator and the pole, a slower westerly jet stream and therefore more frequent blocking events. However, Barnes et al. (2012) question this link, stating that the number of blocking events is very sensitive to the diagnostics used for their identification.

The primary objective of this study is to take advantage of the recently available 110-years (1901-2010) data set to analyze the link between the atmospheric blocking characteristics in the North Atlantic and atmospheric and oceanic climate variables (such as mean sea level pressure, MSLP; 500-hPa geopotential height, 500-hPa GZ; surface air temperature, SAT; sea-surface temperature, SST; and sea-ice concentration, SIC) and atmospheric modes of variability (such as NAO, BWA and AMO). To the best of our knowledge, our study is the first to investigate $\mathrm{NH}$ blocking characteristics over 110 years based on the CERA-20C dataset, and it is the first to investigate the link between BWA, AMO and blocking characteristics over NH. Another objective is to find out whether the time series of $\mathrm{NH}$ blocking characteristics exhibit a significant trend over the last century, based on a reanalysis that includes two-way coupling with the ocean. The CERA-20C dataset (Laloyaux et al. 2018) used in this study was developed by the European Centre for Medium-Range Weather Forecasts (ECMWF). This dataset is produced with the coupled data assimilation CERA system that assimilates surface pressure and marine wind observations, as well as ocean temperature and salinity profiles (Laloyaux et al. 2016). It is worth noting that no data assimilation is performed for the land, wave and sea-ice components; the use of a coupled system, however, ensures a dynamically consistent Earth system estimate at each time. In CERA-20C, ocean observations can have a direct impact on the atmospheric analysis and, conversely, atmospheric observations can have an immediate impact on the analyzed state of the ocean within the same assimilation cycle (Laloyaux et al. 2018). Note that CERA-20C differs from the ERA-20C reanalysis (Poli et al. 2016) that was used in the study of Messori et al. (2016). ERA-20C is an atmospheric-only reanalysis that assimilates conventional observations of surface pressure and marine wind, and of SST as well (see Poli et al. 2016). Considering the nature of interactions between atmospheric and oceanic features over the North Atlantic and their roles on North American and European meteorological and climatic conditions, the coupled CERA-20C reanalysis product provides a valuable source of data for our study.

\section{Data and methods}

\subsection{Data sets and study region}

CERA-20C reconstructs the past weather through a 10-member ensemble of reanalyses using a new data assimilation system based on a method that simultaneously ingests atmospheric and ocean observations into a coupled Earth system model (Laloyaux et al. 2016), thus naturally taking into account air-sea interactions. Hence, ocean observations can have a direct impact on the atmospheric analysis and, conversely, atmospheric observations on the analyzed state of the ocean. To limit the impact of changes in the observing system throughout the century, only conventional surface atmospheric observations have been used (Laloyaux et al. 2016).

CERA-20C data are available for the period spanning January 1901 to December 2010, at a 3-hourly time interval, 125-km horizontal resolution (same resolution of ERA20C) and 91 levels in the vertical between the surface and $0.01 \mathrm{hPa}$ (Laloyaux et al. 2016). To produce this dataset, the entire period was divided into 14 different streams of 10 years each, each production stream being initialized from the uncoupled reanalyses ERA-20C; the first 2 years of each production stream was discarded for spin-up to produce the final dataset (Laloyaux et al. 2016).

The quality of CERA-20C has been evaluated against other centennial reanalyses and independent observations (see https://www.ecmwf.int/en/elibrary/17932-evaluation -and-diagnostics-cera-20c-climate-reanalysis-ensemble). Results show significant improvements in the accuracy of the troposphere data compared to previous reanalysis products (ERA-20C and 20CRv2c; see Laloyaux et al. 2018), notably for the representation of atmosphere-ocean heat fluxes and 
mean sea level pressure. More details about the assimilation method used to produce CERA-20C are described in Laloyaux et al. (2016, 2018).

In this study, we used the daily variables from CERA20C, including MSLP, 500-hPa GZ, 2-m (near surface) SAT, SST and SIC. Downloading atmospheric and oceanic variables for the ten available CERA-20C members would have been excessively time-consuming and storage-demanding; therefore, one member of the ensemble (member 0) was selected for this study.

In this study, atmospheric blocking events and their corresponding climatology were computed for the entire $\mathrm{NH}$. However, the dependence between blocking events and atmospheric and oceanic teleconnection indices will be studied only over the Atlantic sector $\left(0^{\circ}-100^{\circ} \mathrm{W}, 35-90^{\circ} \mathrm{N}\right)$.

\section{Methodology}

\section{(a) Blocking index}

Due to the range of circulation patterns that have been interpreted as blocking, there is no universally accepted definition or metric for blocking. Consequently, the different indices do not necessarily give consistent statistics (Barnes et al. 2012, 2014; Woollings et al. 2018). Blocking indices differ from each other by the use of different meteorological variables. Some of them used, for example, the 500-hPa GZ (e.g., Lejenäs and Økland 1983; Tibaldi and Molteni 1990), the vertically averaged potential vorticity (PV) (Schwierz et al. 2004) or the potential temperature on a 2-PVunit surface (Pelly and Hoskins 2003). Blocking indices also included various tunable parameters, including duration and amplitude thresholds, which are often different across studies. The most serious limitation of many blocking indices proposed in the literature is that they do not take account of the propagation and spatial structure of blocking events, thereby resulting in inconsistent conclusions for different indices (Barriopedro et al. 2006). Moreover, some indices identify teleconnection patterns, open ridges or standing wave fluctuations as blocking events, but an examination of the full field shows nothing that a synoptician would label as a block (Dole and Gordon 1983). To avoid these problems, in this study, the method and algorithm proposed by Barriopedro et al. (2006) was used to detect $\mathrm{NH}$ atmospheric blocking, as this method allows to consistently detect both the individual evolution of blocked flows and identifying coherently persistent blocked patterns. This method also provides additional information on blocking parameters, including the location of the blocking center, the intensity and extension of blocking events (see Barriopedro et al. 2006).

Following the method proposed by Barriopedro et al. (2006), which is a modified version of Tibaldi and Molteni (1990), two 500-hPa height geopotential meridional gradients (GHGN and GHGS, see below) have been computed for each longitude and for each day of the study over the $\mathrm{NH}$, using the following equation:

$$
\begin{aligned}
G H G N & =\frac{G Z\left(\lambda, \phi_{N}\right)-G Z\left(\lambda, \phi_{0}\right)}{\phi_{N}-\phi_{0}} \\
G H G S & =\frac{G Z\left(\lambda, \phi_{0}\right)-G Z\left(\lambda, \phi_{S}\right)}{\phi_{0}-\phi_{S}},
\end{aligned}
$$

where $\quad \phi_{\mathrm{N}}=77.5^{\circ} \mathrm{N}+\Delta ; \quad \phi_{0}=60^{\circ} \mathrm{N}+\Delta ;$ $\phi_{\mathrm{S}}=40^{\circ} \mathrm{N}+\Delta$ and $\Delta=-5^{\circ},-2.5^{\circ}, 0^{\circ}, 2.5^{\circ}, 5^{\circ}$.

$G Z(\lambda, \phi)$ is the $500-\mathrm{hPa}$ geopotential height at latitude $\phi$ and longitude $\lambda$. These two meridional gradients are proportional to the geostrophic zonal wind component and provide a measure of zonal flow intensity for each longitude. A longitude is considered as being blocked if the following conditions are verified for at least one of the five values of $\Delta$ :

$$
\begin{array}{ll}
G H G N<-10 \mathrm{gpm} /{ }^{\circ} \text { lat } & \left(C_{1}\right) \\
G H G S>0 & \left(C_{2}\right) \\
G Z\left(\lambda, \phi_{0}\right)-\overline{G Z}\left(\lambda, \phi_{0}\right)>0 & \left(C_{3}\right)
\end{array}
$$

where $\overline{G Z}$ is the climatological mean $500-\mathrm{hPa}$ GZ for the 1901-2010 time interval. The first condition $\left(\mathrm{C}_{1}\right)$ provides a measure of zonal flow intensity; $\mathrm{C} 1$ being satisfied ensures that the flow is westerly with some minimal intensity to the north. The second condition $\left(C_{2}\right)$ ensures that the flow is easterly to the south. The last condition $\left(\mathrm{C}_{3}\right)$ ensures that the situation corresponds to a ridging anomaly, thus distinguishing the $\mathrm{NH}$ blocking from cut-off lows that are not considered as blocking events. In addition to the previous conditions, the following two filters are required for a blocking pattern (Barriopedro et al. 2006), namely:

- Spatial filter Since blocking anticyclones are largescale systems, a blocking pattern is identified when five or more contiguous grid cells are simultaneously blocked. Note that this filter allows one nonblocked longitude between two blocked longitudes. This filter is imposed in order to include those blocking patterns showing non-blocked longitudes under an anticyclone area.

- Temporal filter A minimum duration of 5 days threshold is used to define a blocking event, given 
that blocking pattern can persist from several days to several weeks.

By applying the criteria above, and using the automated single blocking detection algorithm presented in Barriopedro et al. (2006), blocking anticyclones were initially detected, and blocking center position is taken to be the maximum height grid point within the blocked region. Blocking episodes were characterized by several indices including: (1) the date of occurrence, the first eastern blocked longitude, (2) the duration of events (by days), (3) the spatial extension of events evaluated as the number of blocked longitudes, and (4) the intensity of blocking episodes taking values between 1 and 10, with increasing values being stronger blocking events (e.g., Barriopedro et al. 2006; Wiedenmann et al. 2002). This latter is computed by normalizing the local maximum height geopotential (at the blocking center) with a mean line obtained by averaging the lowest trough axis downstream and upstream heights located at the same latitude of blocking center. Note that to compute the characteristics of blocking events, the daily parameters (maximum longitudinal averaged height, maximum latitudinal averaged height, the first eastern blocked longitude, the extension, and the intensity) were averaged for the whole life cycle of a blocking episode.

\section{(b) Teleconnection indices}

- Three teleconnections indices-NAO, BWA and AMO — were used in the present study and computed over the 1901-2010 period at a monthly scale using CERA-20C data:

- The AMO index was computed using the North Atlantic SST anomalies in the area between $0^{\circ}$ to $60^{\circ}$ $\mathrm{N}$ and $0^{\circ}$ to $80^{\circ} \mathrm{W}$ (Trenberth and Shea 2006). The global warming (global mean SST) of all oceanic basins (from $60^{\circ} \mathrm{S}$ to $60^{\circ} \mathrm{N}$ ) was subtracted from the AMO index of 1901-2010, and AMO monthly anomalies averaged relative to 1901-1970, as in Trenberth and Shea (2006).

- The NAO index is that of Hurrell (1995) and was computed based on MSLP time series.

- The BWA index was computed using the method developed by Shabbar et al. (1997) from the GZ-500 hPa daily time series.

\section{(c) Time aggregation and statistical analysis}

After computing blocking occurrence and climate indices per month, seasonal anomalies of each index were computed for the entire 1901-2010 period. For each month of the year, a climatology was calculated based on the 1901-2010 dataset. Then, the monthly climatologies were subtracted from each corresponding month of the whole time series to arrive at the monthly anomaly. Seasonal anomaly was calculated as the average of monthly anomaly across the respective seasons: JFM (January-February-March) for winter, AMJ (April-May-June) for spring, JAS (July-AugustSeptember) for summer, and OND (October-November-December) for fall. Note that the calendar seasons (JFM-AMJ-JAS-OND) were used in this study because its link to winter conditions and its seasonality in oceanic areas. To better represent the teleconnections index phase, as well as to compare values irrespective of the specific standard deviation of each index, anomalies of teleconnections indices were normalized by their standard deviation.

The non-parametric Mann-Kendall (MK) (Mann 1945; Kendall 1948) test has been widely used in climatology for trend detection. The MK test is based on the observations rank. It is often preferred over other statistical tests because of its robustness and power in slow phenomena data trends, which can be the case with blocking characteristics. A challenging problem with the MK test is that the result is affected by the autocorrelation structure of the time series analyzed (Douglas et al. 2000; Zhang et al. 2001; Khaliq et al. 2008, 2009). In fact, in such a situation, the MK test suggests a significant trend that is often compared to an independent time-series. To overcome this problem, several approaches were proposed in the literatures (Douglas et al. 2000; Khaliq et al. 2008, 2009). In this study we use the approach proposed by Douglas et al. (2000) and Khaliq et al. (2008). This approach is based on three steps in which an autocorrelated time series is "prewhitened" (von Storch 1995; Kulkarni and von Storch 1995) before conducting the MK test: (1) we compute the $r_{1}$ 1-lag autocorrelation coefficient of the time series, (2) if $r_{1}$ is nonsignificant at a chosen significance level (normally taken to be 5\%), we apply the MK test to the original time series, otherwise (3) the MK test is applied to the time series, after the autocorrelation has been removed. To estimate the magnitude of the trend in the prewhitened time series, the Sen's slope estimator (SS) (Sen 1968) was used. This latter is a nonparametric technique insensitive to outliers and more accurate than simple linear regression for skewed and heteroskedastic data.

To characterize the dependence between blocking events and climate variables, we used the non-linear Spearman (ranked) correlation (Spearman 1904). This correlation method assumes no particular distribution of the data, which is not the case with the linear Pearson correlation that assumes Gaussian distribution. Since correlation is based on observations, several physical events can be 
highly correlated with no causation. This can be the case, for example, when two physical events occur at the same time but one event does not necessarily cause the other event to happen (Sugihara et al. 2012). Therefore, in this study, a test of causality based on predictability instead of observations was made between teleconnection indices and blocking characteristics (i.e., occurrence, duration, intensity and extension). There are many effective methods to infer the causal relation between the variables (Folland et al. 2001; Granger 1969; Schiff et al. 1996; Sugihara et al. 2012). The Granger causality (Granger 1969) is one of the most widely used methods. However, this method lacks ability to detect the causal relation on nonlinearly coupled systems, such as the climate system. In order to overcome these drawbacks, Sugihara et al. (2012) proposed the convergent cross mapping (CCM) method based on the Takens' theorem (Takens 1981). The main idea behind this theorem is that if $X$ does influence $Y$, then the causal variable $X$ can be recovered (reconstructed, predicted) from the historical record of the affected variable Y. The correlation coefficient between reconstructed (predicted) and observed values of $\mathrm{X}$ is called cross map skill and is denoted as rho $(\rho)$. This value quantifies the accuracy of the reconstruction of $X$ from $Y$ and varies between 0 (no coupling between the two systems or variables) and 1 (strong coupling between the two systems or variables). Usually, the reconstruction of $\mathrm{X}$ is not possible when $\mathrm{X}$ does not affect $\mathrm{Y}$. However, if X and $\mathrm{Y}$ are strongly synchronized, $\mathrm{X}$ might be reconstructed with high accuracy, even in the absence of causal relationships. To distinguish this type of synchronization from true causal relationships, Sugihara et al. (2012) proposed to examine the dependence of the accuracy of the reconstruction on the number of historical observations of $\mathrm{Y}$ used for the reconstruction of $\mathrm{X}$, that defines the length of the library by performing a cross mapping for a range of values varying from the smallest to the maximum possible library size. The causal effect of $\mathrm{X}$ on $\mathrm{Y}$ can be inferred if the cross-map skill increases and converges with the size of the library. To test if the causality is statistically significant, for each possible library size, a 100 randomly sampled observation set was generated, then the mean and the standard deviation of $\rho$ was computed. The 95\% confidence intervals for estimated $\rho$ for the shortest and longest libraries were calculated and used to determine whether the predictive power has significantly increased. In this paper, rEDM package (https://mran.microsoft.com/ snapshot/2018-06-22/web/packages/rEDM/vignettes/rEDMtutorial.html) was used to test the causality between blocking occurrences and teleconnection indices with the CCM method. CCM has been successfully applied in many climate studies such as in the evaluation of the interaction between greenhouse gases and temperature (van Nes et al. 2015), the relationship between temperature and galactic cosmic rays
(Tsonis et al. 2015), and the causal effect of soil moisture on precipitation (Wang et al. 2018).

\section{Results}

\subsection{Seasonal climatology and trends of blocking events over the $\mathrm{NH}$}

Before presenting the results from CERA-20C for the complete 1901-2010 time period, we first present a brief overview and comparison of the blocking characteristics for a common time period (1961-2010) from the CERA-20C reanalysis and two other reanalyses: NCEP-NCAR, National Centers for Environmental Prediction-National Center for Atmospheric Research (Kalnay et al. 1996), and ERA-20C, ECMWF's first atmospheric reanalysis of the twentieth century (Poli et al. 2016) (see Table 1). The spatial distribution of the blocking event centers is shown in Figure S1 (see online supplemental material). We find a slightly higher frequency of blocking events in the CERA-20C reanalysis compared with those from NCEP-NCAR and ERA-20C (Table 1). In addition, blocking events in CERA-20C last longer, are broader in space and more intense than those obtained from the NCEP-NCAR and ERA-20C datasets. These differences may be due to the fact that the CERA$20 \mathrm{C}$ product is from a fully coupled ice-ocean-atmosphere model (Laloyaux et al. 2016). Alternatively, it may be due to potential effects of high-frequency interactions between atmospheric and oceanic states, not explicitly included in the common atmospheric-only reanalysis products (see further details in Laloyaux et al. 2018). Moreover, the spatial resolution of CERA-20C reanalyses is twice that of NCEPNCAR (125 km versus $250 \mathrm{~km}$, respectively), which could also explain some of these differences, as resolution affects both the atmospheric flow (500-hPa GZ) and lee waves near important topographic features, such as the Greenland where North Atlantic blocking occurs over both the Greenland ice sheet's physical barrier and the Nordic-seas (see Hahn et al. 2020; Zhang and Luo 2020). As shown in Rohrer et al. (2020), genesis and lysis of blocking events tend to be detected earlier and later with high-resolution datasets, respectively. Note also that blocking characteristics derived from NCEP-NCAR and ERA-20C (reported here) are similar to those reported in the literature using the same products (e.g., Barriopedro et al. 2006; Lupo et al. 2019; Laloyaux et al. 2016).

The full 1901-2010 time period (110 years) comprises a total of 3630 blocking events (an average of about 33 events/years), for a total duration of 34,800 days over the $\mathrm{NH}$, (corresponding to a mean duration of 9.5 days/event), a mean intensity of 2.4/events and a mean extension of 28 degrees of longitudes (Tables 2 and Figure S2 in the online 


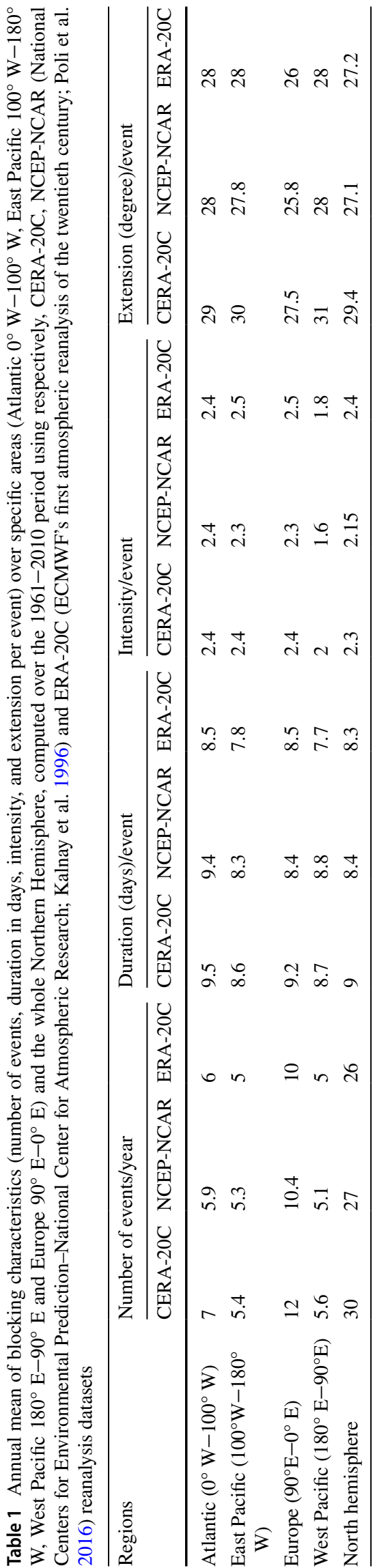

supplemental material). We found that the mean number of blocking events before 1960 (approximately 36 events/year) is larger than after 1960 (approximately 30 events/year). Several studies have also found higher numbers of blocking events in the early part of the twentieth century (e.g., Mokhov et al. 2012). In fact, as mentioned in Rohrer et al. (2019), differences in number of blocking events between reanalyses before 1950 could be related to the spread in the simulated GZ500 (Slivinski et al. 2019), especially for highlatitude regions where observations are sparse and limited, in particular before the Second World War.

Over the whole 1901-2010 period, NH blocking events are more frequent and longer lasting in spring and winter than in fall and summer (see Table 2). The mean seasonal number of blocking events in winter and spring identified using CERA-20C data are also larger than those reported in the literature using the NCEP-NCAR reanalysis dataset. The spatial distribution of blocking events with respect to their intensities per season for the 1901-2010 period is given in Fig. 1. Generally, stronger (more intense) blocking events occur in fall and winter than in spring and summer. The strongest blocking events occur mostly over Europe in winter/fall (see Table 2 and Fig. 1). We also found an above normal blocking events duration during the 1940-1990 period (Figure S3 in the online supplemental material), which corresponds to a positive phase of the BWA (see below for more details about the links between blocking events and teleconnection indices).

Figure 2a shows the blocking center frequency as a function of longitude (i.e., one count by "blocking events") during each season, which corresponds to the number of times by season that a longitude is identified as a blocking center. Generally, as noted previously in Table 2, high number of blocking events occurs during winter and spring, and low number occurs in summer. According to the blocking centers, $\mathrm{NH}$ events can be classified in three sectors: (1) the well-known Euro/Atlantic $\left(260^{\circ} \mathrm{E}-90^{\circ} \mathrm{E}\right.$ in Fig. 2) sector corresponds to the primary blocking region in $\mathrm{NH}$, with two secondary areas of blocking events in (2) the western Pacific sector between $90^{\circ} \mathrm{E}$ and $180^{\circ} \mathrm{E}$, and (3) the eastern Pacific sector between $180^{\circ} \mathrm{E}$ and $260^{\circ} \mathrm{E}$. We also note that blocking events in Euro/Atlantic are generally more intense than those in the Pacific (Fig. 1). Figure $2 b$ shows the seasonal mean blocking frequency in the $\mathrm{NH}$ (expressed in \% of time) as a function of longitude and corresponding to the percentage of blocked days per season (the annual distribution is presented in Figure S2 in the online supplemental material). The solid blue line represents the average across the 110-years period, and the dashed red lines represent the interannual variability ( \pm one standard deviation among all years). There is a maximum blocking activity (high percent of blocked days) near the central Pacific $\left(160^{\circ}-180^{\circ}\right)$ and Atlantic $\left(10^{\circ} \mathrm{W}-10^{\circ} \mathrm{E}\right)$, and a minimum activity (low 
Table 2 Seasonal mean characteristics (number, duration, intensity and extension) of blocking events using CERA-20C dataset, for Atlantic $\left(0^{\circ}-100^{\circ} \mathrm{W}\right)$, East Pacific $\left(100^{\circ}-180^{\circ} \mathrm{W}\right)$, Europe $\left(90^{\circ} \mathrm{E}-0^{\circ}\right)$, and West Pacific $\left(180^{\circ}-90^{\circ} \mathrm{E}\right)$ sectors, as well as the whole Northern Hemisphere

\begin{tabular}{|c|c|c|c|c|c|c|c|c|c|c|c|c|c|c|c|c|}
\hline \multirow[b]{2}{*}{ Regions } & \multicolumn{4}{|c|}{ Number of events } & \multicolumn{4}{|c|}{ Duration (days)/event } & \multicolumn{4}{|c|}{ Intensity/event } & \multicolumn{4}{|c|}{ Extension (degree)/event } \\
\hline & JFM & AMJ & JAS & OND & JFM & AMJ & JAS & OND & JFM & AMJ & JAS & OND & JFM & AMJ & JAS & OND \\
\hline Atlantic $\left(0^{\circ} \mathrm{W}-100^{\circ} \mathrm{W}\right)$ & 2.5 & 2.5 & 1.5 & 2.2 & 10.9 & 10.1 & 7.9 & 9.8 & 2.7 & 1.9 & 1.7 & 2.6 & 32.5 & 28.3 & 21.5 & 28 \\
\hline East Pacific $\left(100^{\circ} \mathrm{W}-180^{\circ} \mathrm{W}\right)$ & 2.1 & 2 & 1.5 & 1.5 & 11.4 & 9.2 & 8.1 & 8.7 & 2.9 & 1.7 & 1.7 & 2.6 & 34 & 25.7 & 22.5 & 29.8 \\
\hline Europe $\left(90^{\circ} \mathrm{E}-0^{\circ} \mathrm{E}\right)$ & 3 & 3 & 2 & 2.2 & 10.8 & 8.6 & 7.6 & 8.7 & 2.9 & 2.1 & 1.7 & 2.7 & 30.3 & 25.8 & 24.2 & 27.4 \\
\hline West Pacific $\left(180^{\circ} \mathrm{E}-90^{\circ} \mathrm{E}\right)$ & 2 & 2 & 1.5 & 1.5 & 10.6 & 9.4 & 8.4 & 9.7 & 2.2 & 1.4 & 1.2 & 2 & 36 & 27.1 & 24 & 31.2 \\
\hline North Hemisphere & 9.6 & 9.5 & 6.5 & 7.9 & 11 & 9.3 & 8 & 9.2 & 2.7 & 1.9 & 1.7 & 2.5 & 32.7 & 26.7 & 23.5 & 28.4 \\
\hline
\end{tabular}

Mean values are computed over the 1901-2010 period for each season (JFM, AMJ, JAS, and OND)

percent of blocked days) in the two regions centred around $100^{\circ}$ (Eurasia) and $250^{\circ}$ (North America). The patterns of annual blocking frequencies derived from CERA-20C (Figure $\mathrm{S} 2$ in the online supplemental material) are in general agreement to those presented in the literature using other reanalysis products (see Colucci and Alberta 1996; Rex 1950). Therefore, we found slightly higher blocking frequencies, especially over the Pacific region (centered around $160^{\circ}$ ), than those obtained using the NCEP-NCAR reanalysis dataset (see Fig. 1 and Box 14.2 in IPCC AR5 2013) and ERA-Interim (see Fig. 1 in Brunner and Steiner 2017). As mentioned above, these differences could be explained by the quality, the resolution and the periods covered by CERA$20 \mathrm{C}$ with respect to other reanalyses.

Seasonal distribution reveals some differences in the preferred blocked regions with the stronger variability among seasons in winter and spring (Fig. 2b), especially over the western Pacific Ocean along the Kuroshio Current, and in western North Atlantic Ocean in the area of the Gulf Stream. The formation and maintenance of blocking events over these sectors have been dynamically attributed to the stormtrack activity occurring downstream of the main continental areas of Asia and North America (Shutts 1983; Tsou and Smith 1990) or along the baroclinic zones and large temperature gradients between cold landmasses and warm waters of western boundary currents through fall to spring months. In the cold seasons, blocking events are relatively frequent over the central Pacific and over the eastern North Atlantic, while the blocking activity is less frequent and intense over the landmasses. During the summer, the Atlantic and Pacific present a reduced blocking activity, and blocking frequency substantially increases over Eastern Europe, between $20^{\circ}$ and $40^{\circ} \mathrm{E}$ (see Fig. 2b).

Summary results of linear trends (Sen's slope estimator) and their MK significance tests using the 110-years time series are given in Table 3 as well as Figures S4, S5 and S6 in the online supplemental material. No significant trend (at the $5 \%$ significance level, i.e., $p$ value $<0.05$ ) is found in the blocking frequencies for different $\mathrm{NH}$ sectors and seasons. An identical result was shown in the literature using different reanalyses and blocking identification methods (Barnes et al. 2014). However, significant trends were found for some blocking characteristics such as the total number of blocking days in spring (for the eastern Pacific and European sectors), summer (for the Atlantic, European and western Pacific sectors) and fall (for the Atlantic sector); and the annual mean and $90^{\text {th }}$ percentile $\left(\mathrm{Q}_{90}\right)$ of blocking intensity in winter (for the western Pacific sector), spring (for the Atlantic and western Pacific sectors), and fall (for the western Pacific sector). As results, even if no significant change in blocking frequencies were found over the 110-years period (1901-2010), those events become more intense and longer across time for some sectors and seasons. These changes in blocking characteristics can be directly related with changes in the mean flow (i.e., zonal or westerly winds) and transient eddies (e.g., poleward shift of the storm track or vorticity fluxes from extratropical storms). The reader is referred to Hwang et al. (2020) for more details on North Pacific blocking formation. This is in agreement with results from forced climate simulations that report increases in future high-latitude blocking duration, following stratospheric sudden warming events, particularly over the Atlantic (Davini et al. 2014; Mitchell et al. 2013), or through vorticity fluxes which vary with seasons due to the different background flow (see Hwang et al. 2020).

In the following, we focus on the blocking activity in the Atlantic $\left(0^{\circ}-100^{\circ} \mathrm{W}\right)$, instead of the entire $\mathrm{NH}$, in order to evaluate more precisely the links with climate indices and variables between eastern North American and Western European areas. To compute the correlation maps, we characterize blocking pattern with an index of blocking occurrence, which is defined as the number of days per month when any longitude in the Atlantic is classified as blocked. This index was also used in the study of Whan et al. (2016) in which the influence of blocking events on extreme temperatures was evaluated. 


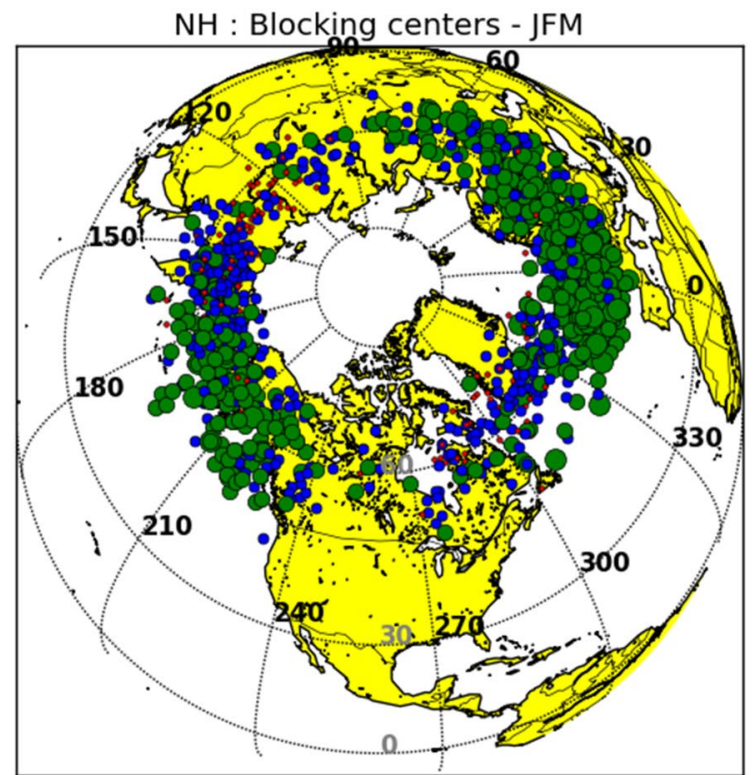

NH : Blocking centers - JAS

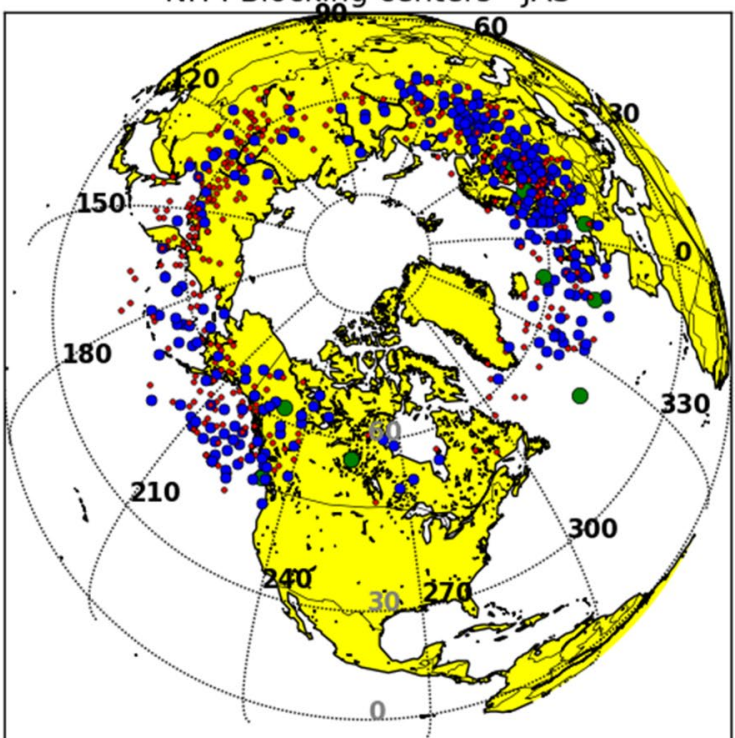

Fig. 1 Seasonal (JFM, AMJ, JAS and OND, from top to bottom panels, respectively) spatial distribution of blocking events for the 110-yr period (1901-2010) over NH. Circles represent the centers of blocking events. Circle sizes are proportional to the intensity of blocking events: Green circles represent stronger blocking events (inten-

\subsection{Links between Atlantic blocking and climate variables: MSLP, GZ-500 hPa, SAT and SIC}

Figure $3 \mathrm{a}, \mathrm{b}$ show the temporal correlation between the North Atlantic blocking occurrence and the seasonal anomalies of MSLP and GZ-500 for the 110-year period, respectively. The areas in white correspond to non-significant correlation (i.e., for $p$ values $>0.1$ ). Throughout fall, winter and spring, the high-latitude region extending from $55^{\circ}$ to $90^{\circ}$ $\mathrm{N}$ and centered over the Greenland records high positive
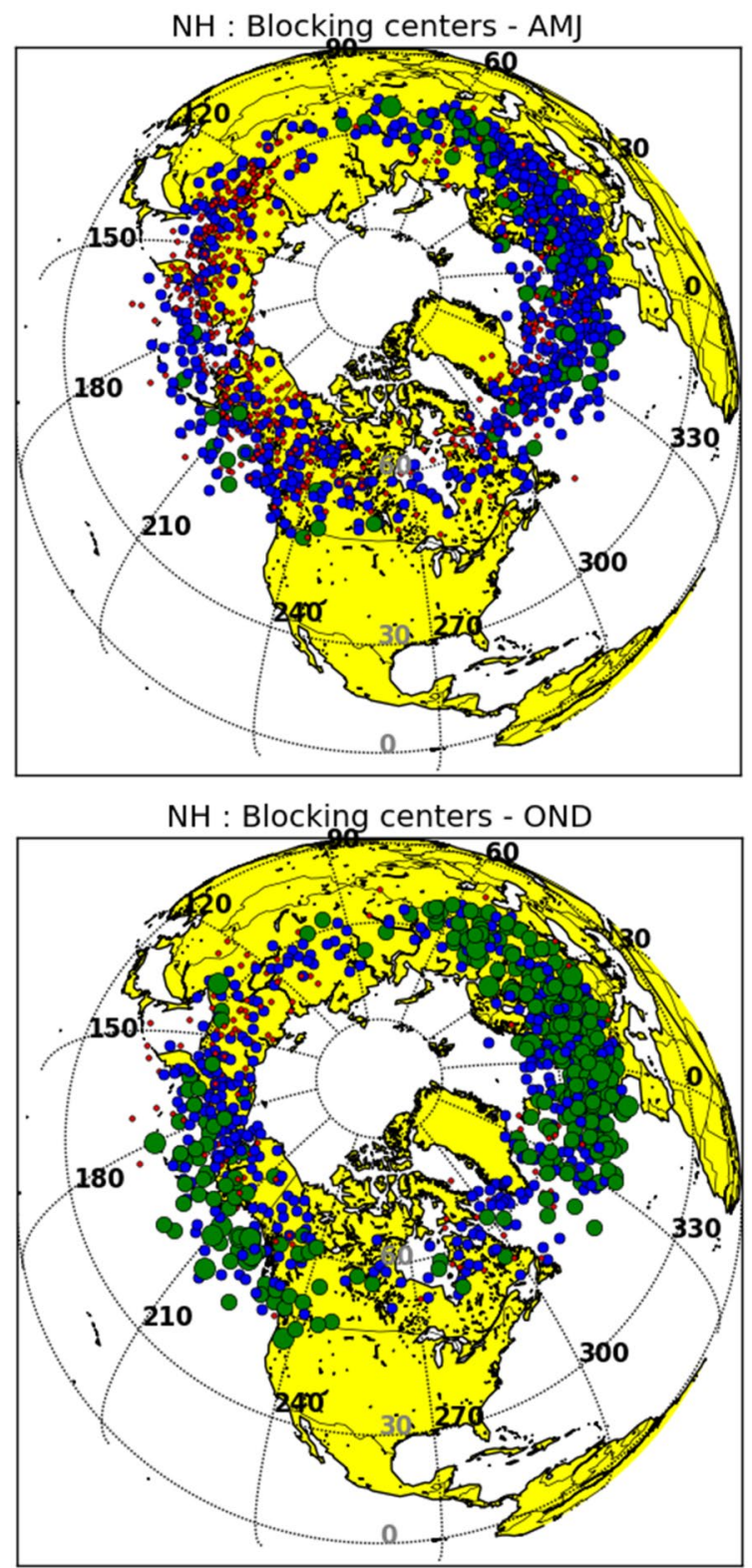

sity $>110$-years mean intensity + one standard deviation), blue circles represent moderate blocking events (intensity fell within one standard deviation of the 110-years mean intensity), and red circles represent weak blocking (intensity $<110$-years mean intensity-one standard deviation)

$(>0.5)$ correlation (red color). This implies that high blocking occurrences in the Atlantic sector are associated with above normal 500-hPa GZ or MSLP in this region. A clear positive correlation is also present over the whole Arctic basin, especially in winter with positive correlation being more pronounced for MSLP than for GZ-500 during Atlantic blocking days or events (see Fig. 3c, d). A zonal response of atmospheric flow from low-levels to mid-troposphere can be seen from the negative correlation between blocking events, MSLP and GZ-500 that covers the whole temperate North 
(a)
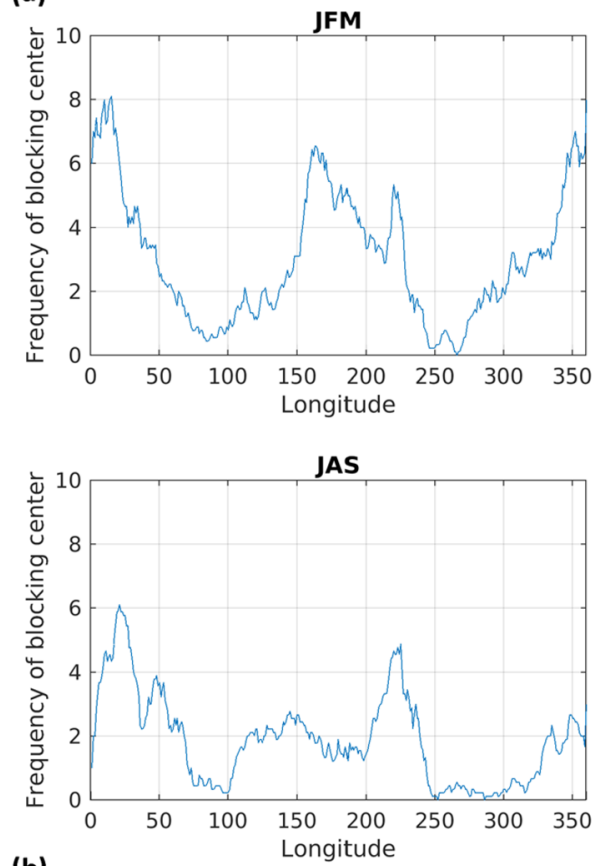

(b)

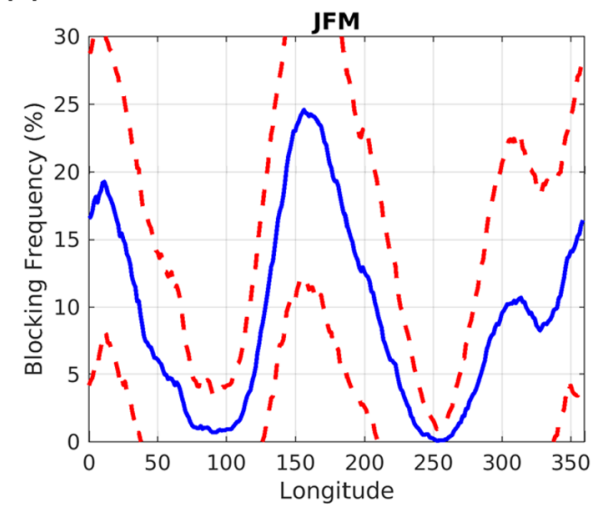

JAS

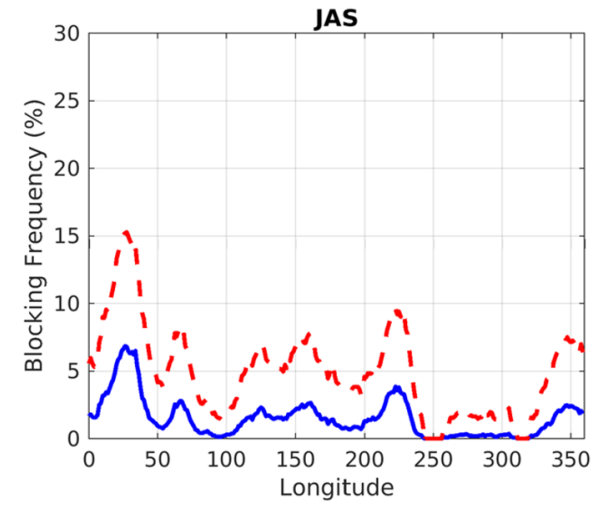

Fig. 2 Seasonal climatology (averaged over the 1901-2010 period) of a the total number of blocking events (i.e., blocking center frequency) per longitudes, and $\mathbf{b}$ the frequency distribution of blocked days (in percentage) for mean (blue solid line) and \pm one standard
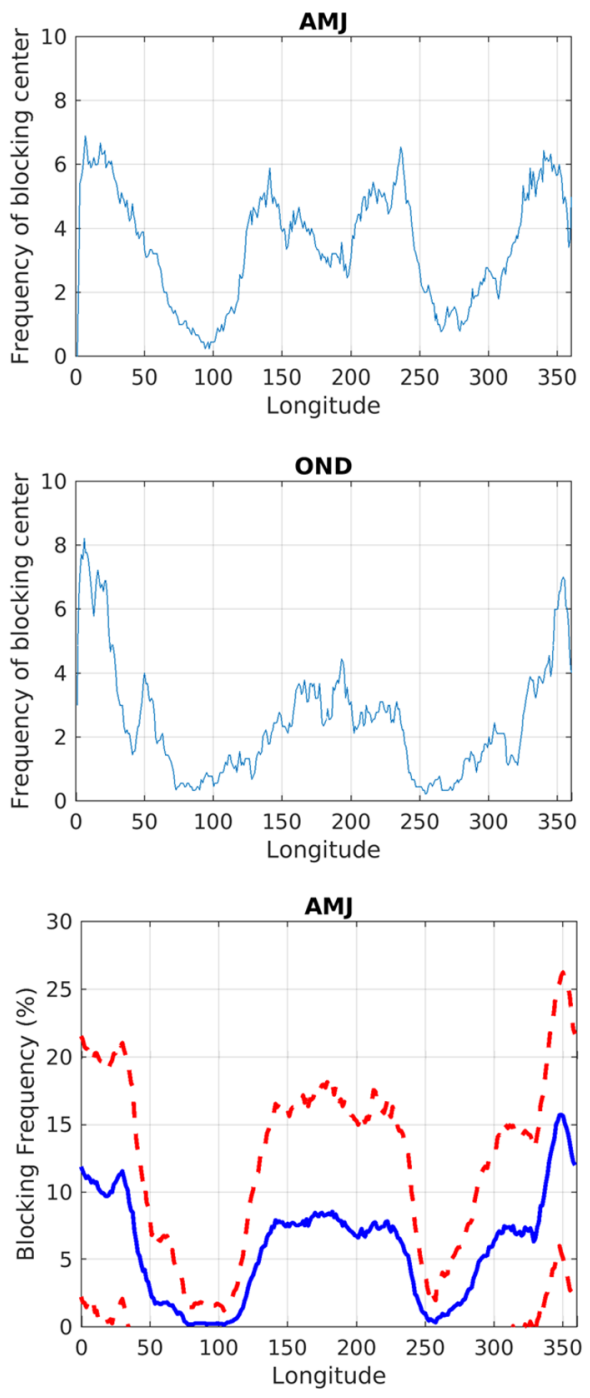

OND

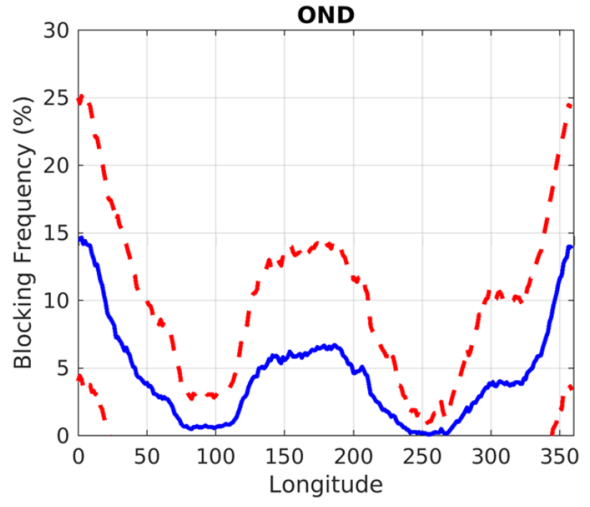

deviation (dashed line) values of blocked days. JFM (January-March) for winter, AMJ (April-June) for spring, JAS (July-September) for summer, and OND (October-December) for fall 
Table 3 Seasonal linear trends of blocking frequencies and characteristics over the 1901-2010 time period

\begin{tabular}{|c|c|c|c|c|c|c|c|c|c|c|c|c|c|c|c|c|c|c|c|c|}
\hline & \multicolumn{4}{|c|}{ Blocking frequencies } & \multicolumn{4}{|c|}{$\begin{array}{l}\text { Annual total blocked } \\
\text { days (days) }\end{array}$} & \multicolumn{4}{|c|}{$\begin{array}{l}\text { Annual mean blocking } \\
\text { intensity (no units) }\end{array}$} & \multicolumn{4}{|c|}{$\begin{array}{l}\text { Annual } Q_{90} \text { blocking } \\
\text { intensity (no units) }\end{array}$} & \multicolumn{4}{|c|}{$\begin{array}{l}\text { Annual mean blocking } \\
\text { spread }\end{array}$} \\
\hline & JFM & AMJ & JAS & OND & JFM & AMJ & JAS & OND & JFM & AMJ & JAS & OND & JFM & AMJ & JAS & OND & JFM & AMJ & JAS & $\overline{\text { OND }}$ \\
\hline Atlantic & - & - & - & - & - & - & 5 & 9 & - & 0.5 & - & - & - & 0.5 & - & - & - & - & - & - \\
\hline East Pacific & - & - & - & - & - & 12 & - & - & 0.3 & 0.45 & - & - & - & - & - & - & - & - & - & - \\
\hline Europe & - & - & - & - & - & 17.5 & 17.5 & - & - & - & - & - & - & - & - & - & - & - & - & - \\
\hline West Pacific & - & - & - & - & - & - & - & - & - & 0.4 & - & 0.55 & 0.5 & - & - & 0.5 & - & _- & - & - \\
\hline
\end{tabular}

'-' represents time series with non-significant trends (using the non-parametric modified Man-Kendall test) at the 5\% confidence level (p value $<0.05)$. Values represent trends for the whole period of 110 years

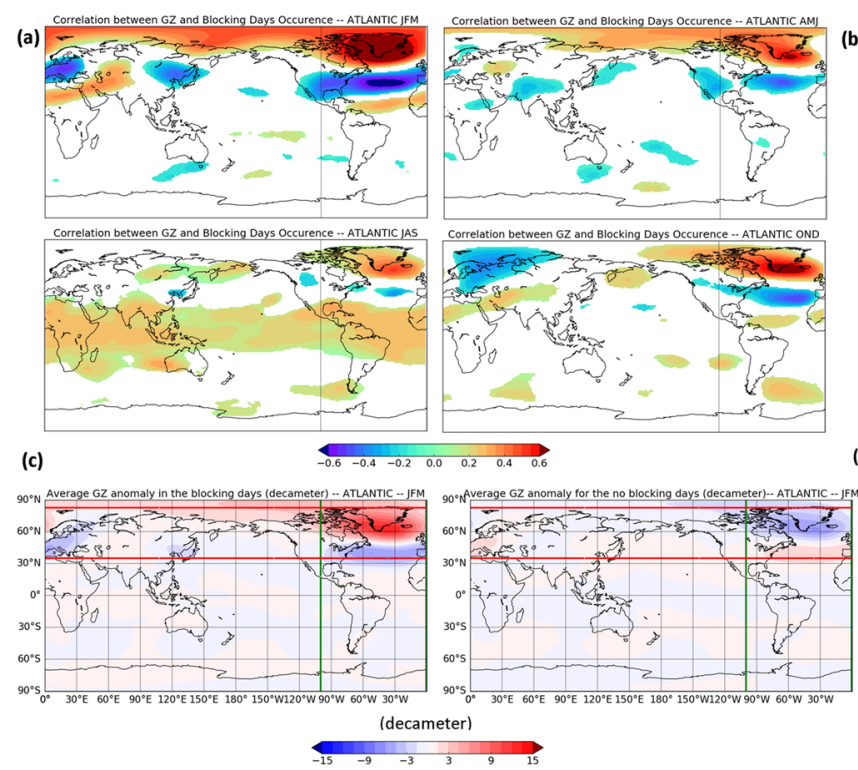

Fig. 3 Seasonal (JFM, AMJ, JAS and OND) non-linear correlation between blocking occurrence in the North Atlantic sector (green lines in panels $\mathrm{c}$ and $\mathrm{d}$ represent the longitude limits of Atlantic sector; and red lines represent the latitude limits of blocking approach

Atlantic, with a signal that extends over the southeastern Eurasia and central Pacific area along the warm Kuroshio Current. We also see a clear negative correlation pattern (lower than -0.5 , in blue, in Fig. 3a, b) over mid-latitude regions of the North Atlantic and Greenland from $30^{\circ}$ to $50^{\circ}$ $\mathrm{N}$ and from $120^{\circ} \mathrm{W}$ toward $30^{\circ} \mathrm{E}$. In this region, blocking occurrences are associated with lower than normal pressure values during cold $\mathrm{NH}$ months and more frequent low-level extratropical cyclones. These patterns of high positive and negative correlation values over the Atlantic as well as North America and Western Europe are clearly representative of a shifted zonal flow, with storm tracks more frequent toward the south during blocking events. In summer, less pronounced correlations emerge with a clear dipole of positive correlation in the North, over the Greenland and Icelandic area, and in the South, over the tropical Atlantic, with a
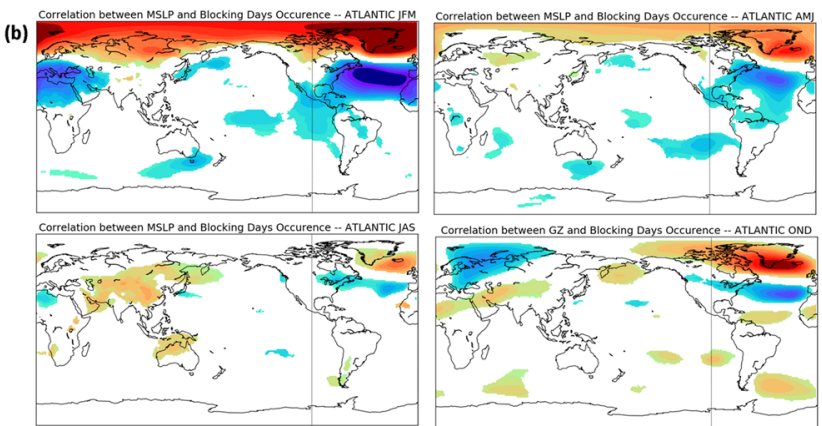

(d)

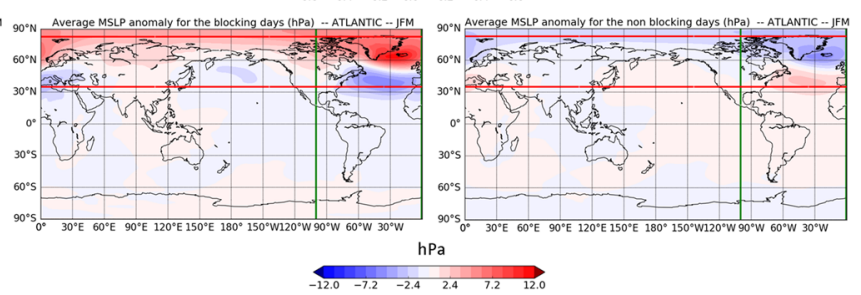

used in this study) and: a 500-hPa GZ anomalies, and b the MSLP anomalies. c, $\mathbf{d}$ represent anomalies in winter during blocked and non-blocked days, respectively, for GZ-500 $\mathrm{hPa}$ (in dam) and MSLP (in $\mathrm{hPa}$ )

propagation towards tropical areas including the continent and the Indian and Pacific oceans. This pattern potentially suggests a link between the main intra-seasonal climatic oscillations in the tropics and the Madden-Julian Oscillation (MJO; Madden and Julian 1994), which controls part of the distribution and sequences of daily weather regimes outside tropical areas (Wheeler and Hendon 2004; Zhang 2005), including potential blocking events and the NAO over the North Atlantic (Cassou 2008).

Figure $3 \mathrm{c}$, d show the 110-year averaged MSLP and GZ anomalies in winter during blocked and non-blocked days. They show that the local pressure/geopotential anomalies are quite sensitive to the occurrence of blocking. Atmospheric blocking is confined in the North with a high-pressure anomaly centered over Greenland and anomalously low pressures across the mid-latitude of the North Atlantic (see Fig. 3a). 
The pattern is reversed (and less pronounced) during nonblocked days. This could be due to various features in the zonal flow versus meridional flow, or due to a poleward shift of the storm track and background of the transient eddies over the North Atlantic. As in classic blocking situations, pronounced geostrophic meridional flow characterizes both the upstream and downstream blocking ridge, extending in longitudes from $75^{\circ} \mathrm{W}$ to $30^{\circ} \mathrm{E}$. During non-blocked days, the MLSP decreases near Iceland (Fig. 3d) because of more intense and/or frequent storms penetrating deep in the Greenland Sea; this leads to warm southerly winds over the Greenland and Barents seas (see links between blocking/ non-blocking events and SAT in the following paragraph).

SAT anomalies are mainly driven by large-scale modes of variability (Guirguis et al. 2011; Wang et al. 2010), including changes in storminess (Messori et al. 2016) and changes in mid-latitude and upper-level tropospheric circulation patterns (e.g., Barnes and Screen 2015). For example, persistent cold spells in winter over North America are associated to cold air advection from the Arctic, and to a very zonal and intense North Atlantic jet shifted toward the south from its climatological location (e.g., Messori et al. 2016). As shown in Fig. 4a, the temporal correlation between the NH Atlantic blocking occurrence and the seasonal SAT anomalies confirms a clear dipole pattern, in both fall and winter, of warm and cold temperature anomalies. A large region of positive correlation is present in northeastern Canada, Labrador Sea, Greenland and Irminger Seas, and over tropical North Atlantic and North Africa, suggesting warm anomalies during blocked days over these areas, as

(a)
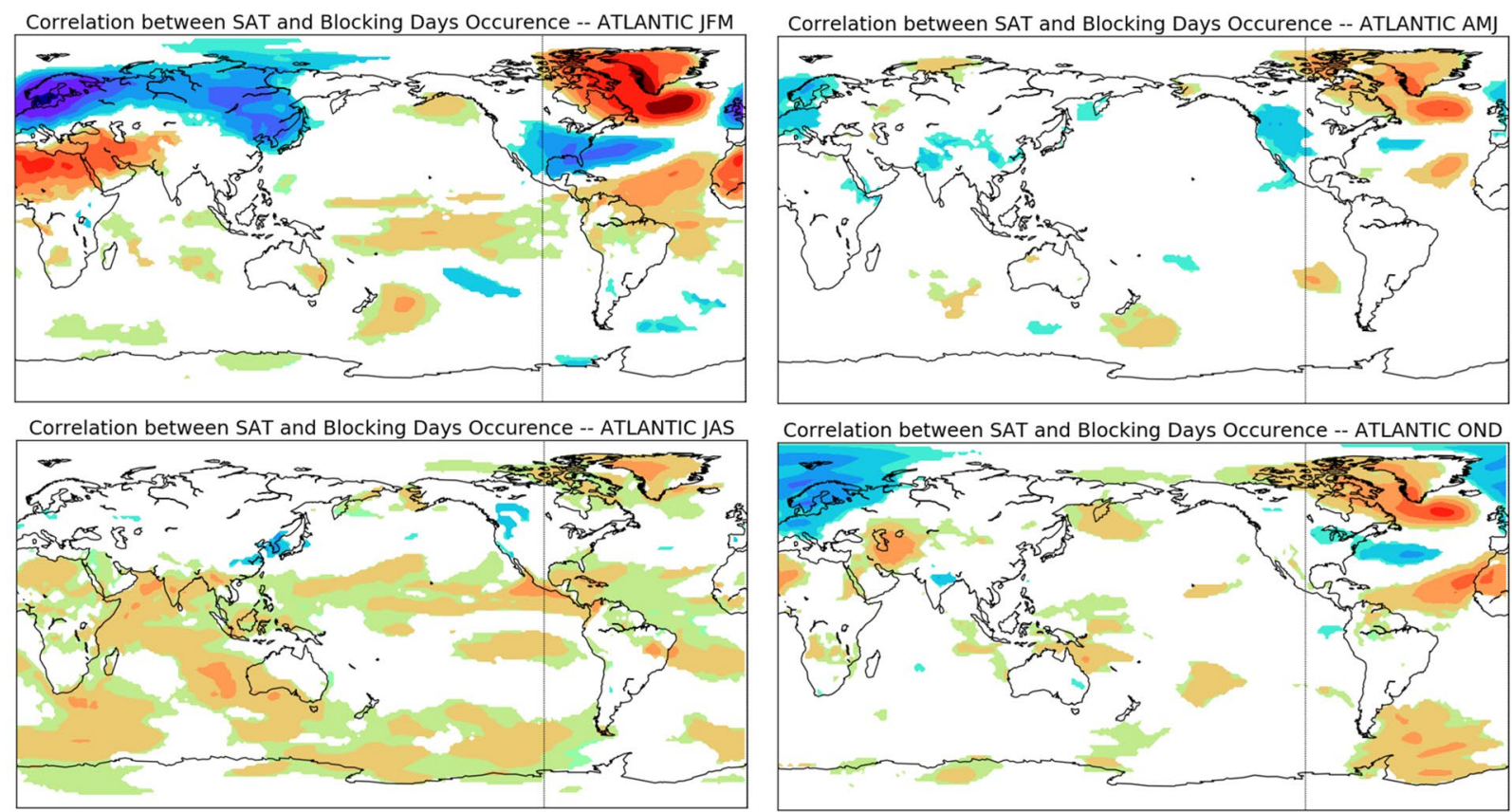

(b)
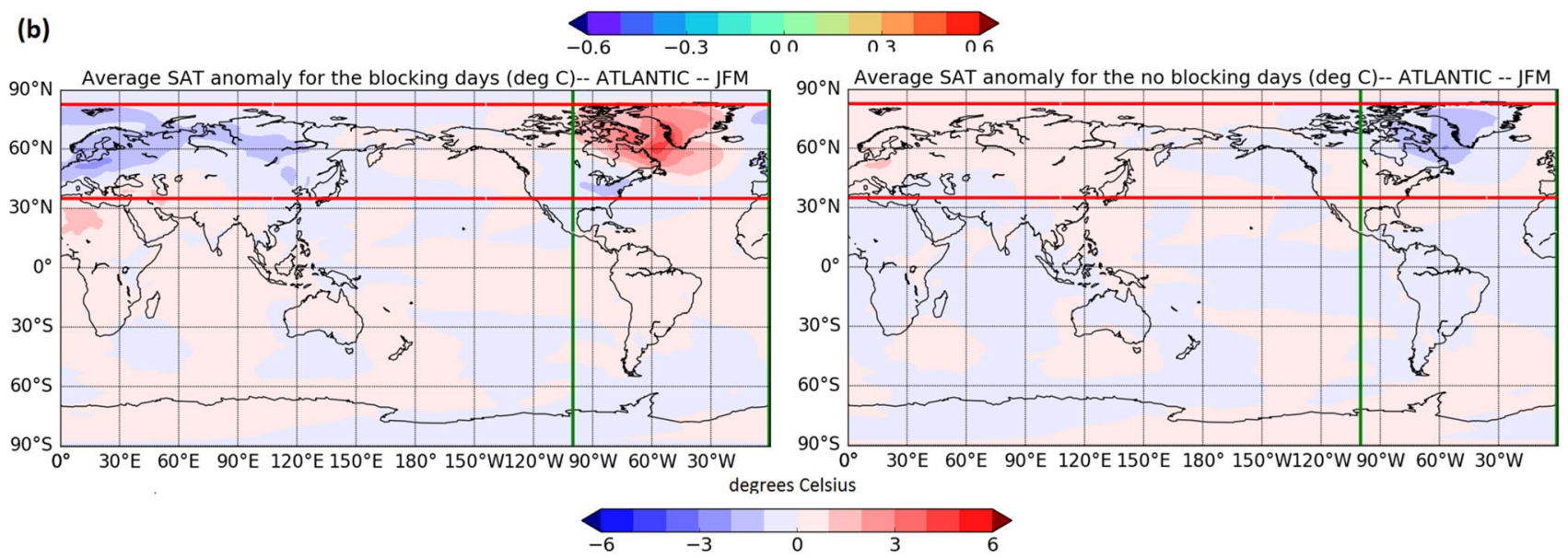

Fig. 4 a Seasonal (JFM, AMJ, JAS and OND) non-linear correlation between blocking occurrence in the Atlantic sector and SAT anomalies and, b the average of SAT anomalies (in ${ }^{\circ} \mathrm{C}$ ) in the winter (JFM) during the blocked and non-blocked days (left and right panels, respectively) 
also noted by Rimbu and Lohmann (2011) and Brunner and Steiner (2017). Conversely SATs decrease with the occurrence of blocked days from the United States toward northern Europe and part of Eurasia (e.g., Sillmann and CrociMaspoli 2009; Stankūnavičius et al. 2017; Trigo et al. 2004). As shown in Fig. 4b, anomalous cold winters in Europe and warm winters in northeastern Canada, Greenland and high latitudes of the North Atlantic occur during blocking events (as shown in Sillmann et al. 2011). During summer, the links are less pronounced over the North Atlantic and continental areas, with warm anomalies over the Indian Ocean and South Pacific during blocked days. There is no evidence of significant correlation between blocked days in the North Atlantic and SAT in summer over Europe, in agreement with Sillmann and Croci-Maspoli (2009) and Brunner and Steiner (2017). However, striking examples are the 2003 European and 2010 Russian heat extremes that resulted from exceptionally long-lasting summer-time blocking events over land, leading to precipitation deficit, pronounced droughts and significant increases in human mortality rates (Black et al. 2004; Dole et al. 2011).

Fluctuations in surface wind, temperature and humidity in the atmosphere can affect the variability in SST over short to long time scales (days to years). However, the influence of North Atlantic SST anomalies on the atmospheric circulation over the North Atlantic remains poorly understood (Robertson et al. 2000). The correlation between northeastern Atlantic blocking occurrence and SST anomalies are similar to the one with SAT anomalies during winter, which are marked by positive correlations in the north and in the south of the North Atlantic, and a negative correlation from the Gulf of Mexico to the eastern North Atlantic (Fig. 5a). This is in agreement with other studies showing that changes in the SSTs over the North Atlantic affect the dynamics and the persistence of blocking events (e.g., O'Reilly et al. 2016; Sampe et al. 2010). However, in the Pacific, Mullen (1989) showed that changes in the SST shift the position of the blocking center but do not affect the persistence of blocking events. Weaker links are present in summer, with stronger relationships between Atlantic blocking and SST anomalies outside the North Atlantic, over the Indian Ocean and South Pacific as for the SAT anomalies (see Fig. 4a).

The SIC over the Arctic and Subarctic regions, which plays a key role in the NH climate system (Barnes and Screen 2015; Francis and Skific 2015), provides complementary information on the anomaly patterns. Figure $5 b$ shows the correlation between SIC anomalies and the North Atlantic blocking occurrence that confirms the seasonal interaction with both SAT and SST anomalies during blocking days. In winter, a dipole pattern of warming/cooling developed with increase blocking occurrences (see Fig. 4) leading to a reduction of SIC from the Canadian arctic ocean, the Hudson Bay, Labrador Sea and Baffin Bay (negative correlation in Fig. 5). However, these patterns induce an increase of SIC in the Baltic, Barents, Kara and Laptev Seas (positive correlation). This is in line with the dipole anomaly that was reported by Venegas and Mysak (2000). The stronger SIC response is observed in winter over the Nordic seas of North America, where the patterns of SAT and SST anomalies are associated with the number of blocked days. During the other seasons, the correlation pattern is less pronounced and extensive than in winter. It is more confined over the Arctic basin and Greenland Sea during spring and summer, and over the Hudson Bay, the Labrador Sea and Baffin Bay during the fall. No significant difference was noted in the SST and SIC anomalies using separately blocked and nonblocked days (not shown).

\subsection{Links between Atlantic blocking, NAO, BWA and AMO climates indices}

The first three panels of Fig. 6a show the 110-years standardized anomalies of the three indices (NAO, BWA and AMO indices) during the extended winter (December to March). The anomalies of the other seasons are not shown because the correlations between the blocking index and climate indices are less statistically significant than in winter. In Fig. 6a, the black curve represents the year-to-year signal and the green curve represents the decadal signal obtained with an 11-year moving average. The NAO, which is a dominant atmospheric mode of variability over the Atlantic, reached maximum values and quasi-systematic positive values in the 1980s and in 1990s, returning to moderately weak positive and negative fluctuations since early 2000s. Two main positive NAO phases, from 1901 to 1935 and from 1975 to 2010, and the negative phase from 1950 to 1975, characterize the main features of the whole time series. Similarly, but with an opposite sign, the BWA index presents two negatives phases, from 1901 to 1938 and from 1982 to 2010, and one longer positive phase from 1939 to 1981 . The negative BWA index values are in general correlated with the downward trend in the SAT over the northeastern coast of North America and the west coast of Greenland (Shabbar et al. 1997). Moreover, a high negative correlation between BWA and NAO indices (around - 0.7) suggests a strong link between midtropospheric pressure anomalies in the west, and MSLP anomalies in the eastern North Atlantic. According to data illustrated in Fig. 6a, NAO is in its positive phase when BWA is in its negative phase, and vice versa, as suggested by Shabbar et al. (1997).

Regarding the AMO index, two negative phases, from 1901 to 1929 and from 1967 to 1995 , and two positive phases, from 1930 to 1966 and from 1996 to 2010, characterize the time series. During the 2000s, the tropical North Atlantic SSTs were in an unprecedented warm state in summer, fall and winter (from October to June) (Fig. 6a). In 
(a)
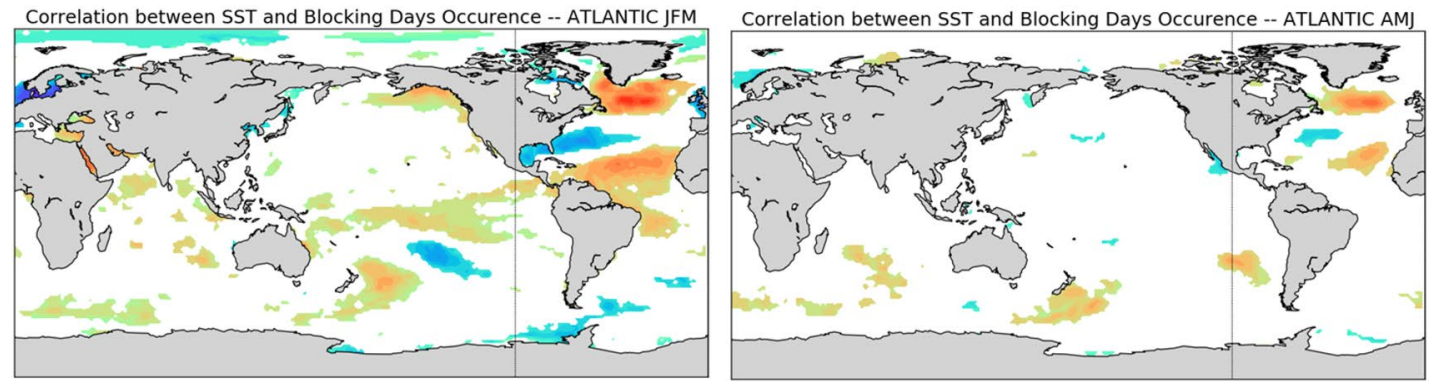

Correlation between SST and Blocking Days Occurence -- ATLANTIC JAS

Correlation between SST and Blocking Days Occurence -- ATLANTIC OND
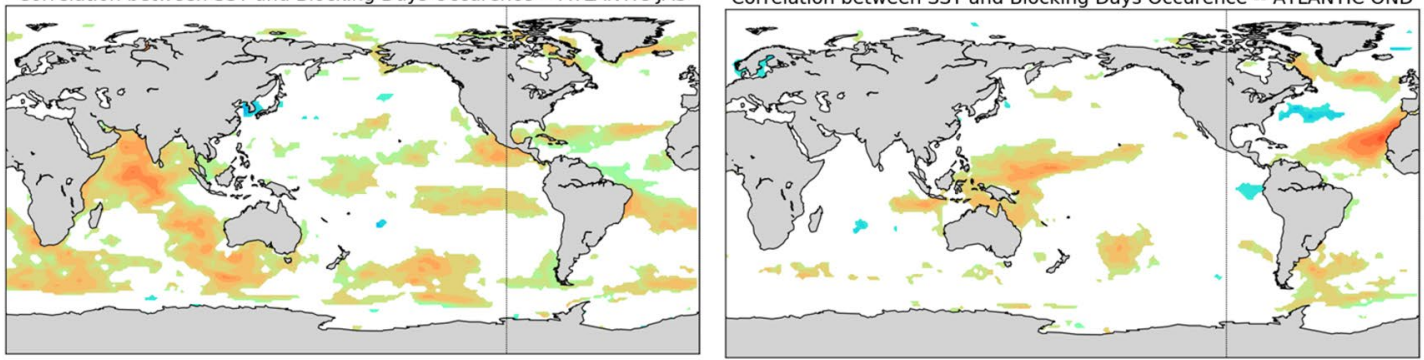

(b)

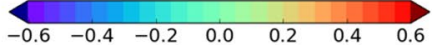

Correlation between SIC and Blocking Days Occurence -- ATLANTIC JFM

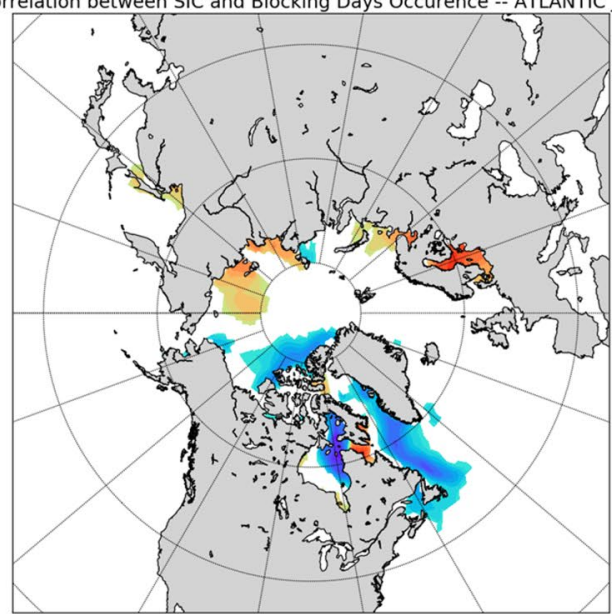

Correlation between SIC and Blocking Days Occurence -- ATLANTIC JAS

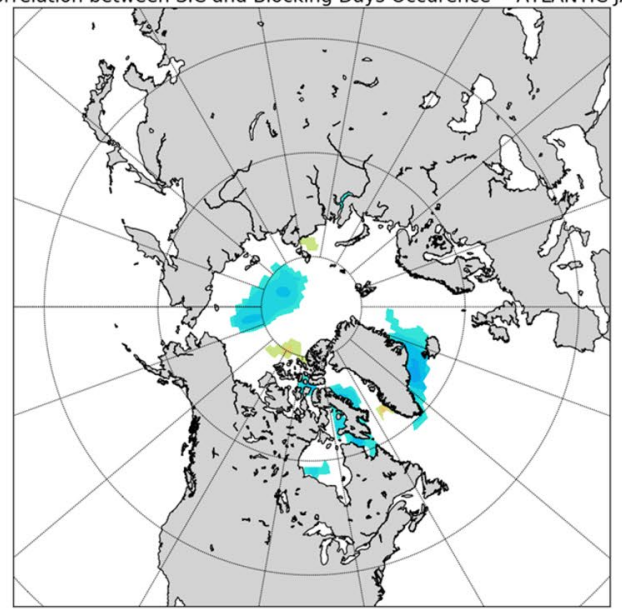

Correlation between SIC and Blocking Days Occurence -- ATLANTIC AMJ

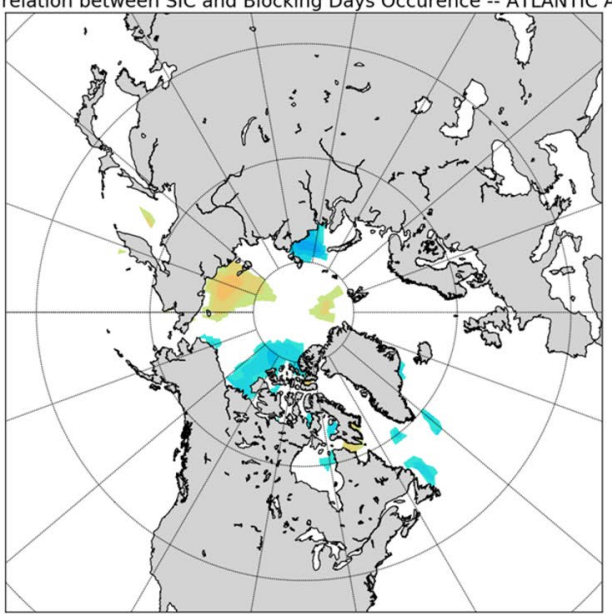

Correlation between SIC and Blocking Days Occurence -- ATLANTIC OND

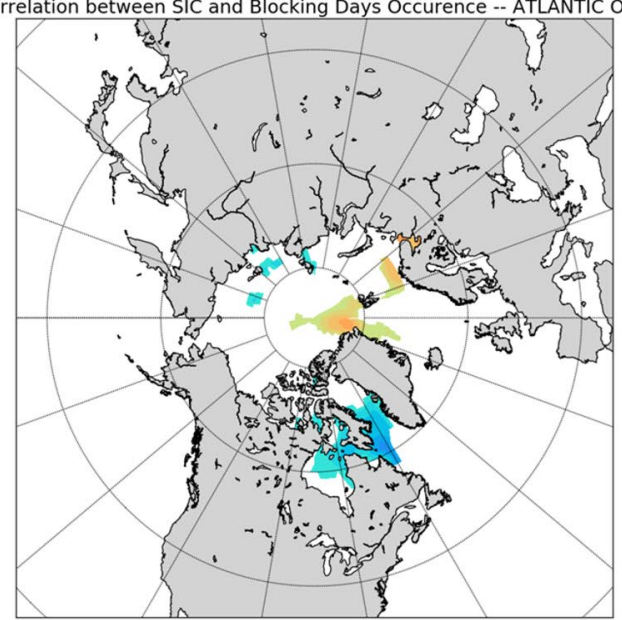

\begin{tabular}{lllllll}
\hline-0.6 & -0.4 & -0.2 & 0.0 & 0.2 & 0.4 & 0.6
\end{tabular}

Fig. 5 Seasonal (JFM, AMJ, JAS and OND) non-linear correlation between blocking occurrence in the Atlantic sector and: a SST anomalies, b SIC anomalies 

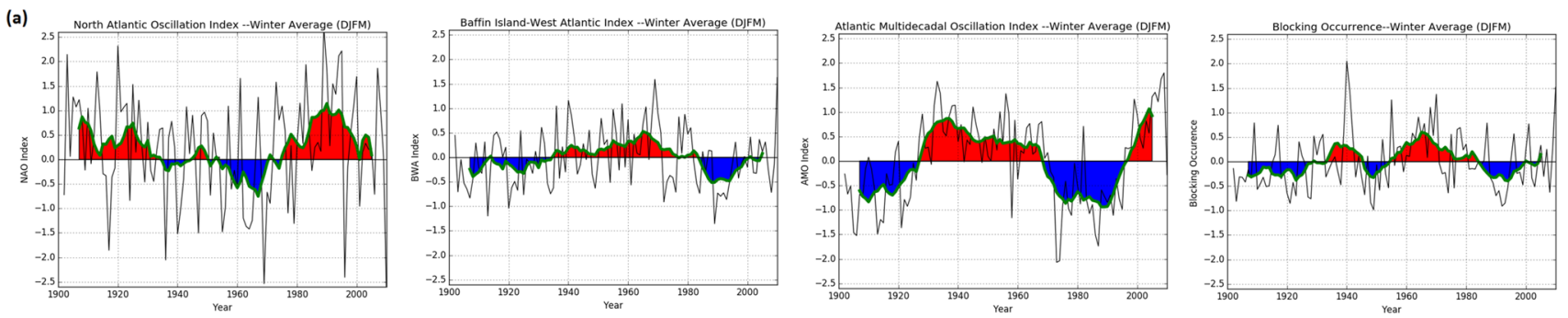

(b)

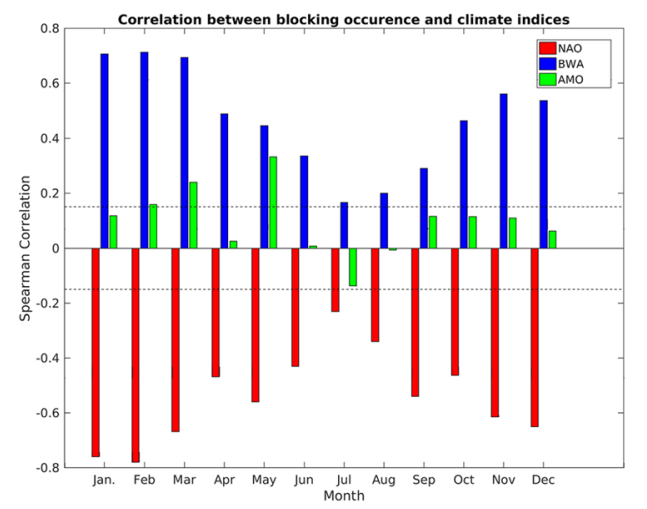

Fig. 6 a Extended winter (DJFM) average standardized anomalies of climate indices (NAO, BWA and AMO) and of blocking occurrence in the Atlantic sector for 1901-2010 from left to right panels, respectively. AMO was computed using the method presented by Trenberth and Shea (2006). NAO and BWA anomalies were calculated and standardized using the entire time series. Black curves represent the year-to-year signal and green curves represent the decadal signal from an 11-years moving average. b Monthly correlation between climate indices and $\mathrm{NH}$ Atlantic blocking occurrence for the entire period. Correlation values $>|0.16|$ (black dashed lines) are statistically significant at the $10 \%$ confidence level (i.e., $p$ value $<0.1$ )
2005, the North Atlantic hurricane season encompassing from June to November was the strongest recorded, and was related to unusually warm SSTs, as shown in the study of Trenberth and Shea (2006).

The right (left) panel of Fig. 6a shows the standardized anomaly of North Atlantic blocking occurrences in extended winter, revealing important interannual and decadal variabilities. In general, an increase in the blocking frequency with positive anomalies occurs during the negative phases of NAO or the positive phases of BWA, and vice versa (e.g., Scherrer et al. 2006). Figure 6b confirms that the monthly non-linear correlation between the Atlantic blocking occurrence and both the NAO and BWA indices are strong ( $|r|>0.4)$ for almost all months and especially in winter ( $|r|>0.6)$, but are weaker in July and August. Highly significant positive/negative correlations are shown between blocking occurrence and BWA/NAO. Linkages between the blocked days and the NAO were also suggested in the studies of Shabbar et al. (2001) and Rimbu et al. (2014), at both interannual and decadal scales. As noted in Häkkinen et al. (2011), the unblocked regime in the Atlantic accompanied with positive NAO index is dominated by the subpolar jet with more meridional storm tracks over the eastern North Atlantic. Conversely, the blocked regime with negative NAO is characterized by a more zonal pattern with continuous jet crossing at subtropical latitudes, and without subpolar jet or storm track over the eastern North Atlantic.

During the winter season, the correlation between NAO and BWA indices is approximately -0.7 , indicating that the variability in the NAO explains only half $\left(0.7^{2}\right.$, i.e., around $50 \%$ ) of the variance in the BWA. In some situations, the BWA patterns provide more precise links to the climate of the North Atlantic in general (see Shabbar et al. 1997), including to the Atlantic blocking occurrence not systematically captured by the NAO. This is the case during the 1970-1981 period where the decadal signal (i.e., 11-years moving average in Fig. 6a) of the NAO index is in its positive phase. In such a case (with a strong negative correlation with blocking occurrence, see Fig. 6b), a decrease in the blocking frequency is usually expected over the North Atlantic which is not the case during this decadal period (as shown in Fig. 6a). Therefore, for this decade (1970-1981), the NAO phase alone does not provide a clear indication of the potential state of the blocking activities over the North Atlantic, in particular during a transition phase between negative and positive phases of NAO. As shown in CrociMaspoli et al. (2007), the synoptic-scale wave-breaking precedes both the establishment of the NAO and the blocking events over the North Atlantic, originating from the west to east flow (i.e., from the western North Atlantic). 
Furthermore, as noted in Shabbar et al. (2001), the surface temperature contrast between land and sea favors the formation and persistence of blockings, especially over the western North Atlantic Ocean (i.e., along the North America coast), where the highest temperature gradients over the whole North Atlantic are located in average. This BWA location and its patterns reveal a clear link with SAT, SST and SIC in these sectors of the North Atlantic, along with the blocking occurrence. Hence, as shown in the patterns and tracks of North Atlantic blocking in the study of Croci-Maspoli et al. (2007), the genesis region of blocking around Nova Scotia (eastern Canada) and the corresponding location of minor blocking frequency maxima over the North Atlantic (the other is over Scandinavia) is more directly linked with the location of the BWA index. This latter location is in phase with both intermittent and recurrent locations of storm tracks over eastern North America (see Poan et al. 2018) and with blocking genesis and tracks (see Fig. 6 in Croci-Maspoli et al. 2007), along with the general cycle or low frequency variability of blocking occurrence (see Fig. 6a).

The correlations between blocking anomalies and the AMO index are weaker than with the NAO and BWA indices. The correlations between AMO and blocking occurrences are nevertheless statistically significant (positive) in several months (February, March and May). They also increase to about 0.5 with a lag of 6-10 years in the AMO (Figure S7 in the online supplemental material). This is similar to the results found recently by Kwon et al. (2020). Häkkinen et al. (2011) also argued that multidecadal variations of the blocking frequency in the North Atlantic were related to $\mathrm{AMO}$, and that wind forcing associated to the blocking variability from Greenland to Western Europe leads to warmer conditions in the subpolar Atlantic Ocean as well as in the tropical and subtropical Atlantic. A delayed response of atmosphere to the AMO can be caused by several factors. For example, as shown in the recent study of Yang et al. (2020), Atlantic warm SST anomalies of AMO could initiate anomalous cooling in the equatorial central-eastern Pacific through atmospheric teleconnections, which could induce other middle- to longer-term effects on blocking areas and quasi-stationary Rossby wave features (Mann et al. 2017). Moreover, as the Atlantic Ocean plays a determining role in the multidecadal variability of global SSTs (Yang et al. 2020), numerous cascade influences are possible. Trenberth and Shea (2006) have demonstrated that the AMO has a lower frequency variability than the known variability in the NAO or atmospheric teleconnection patterns over the NH (see also Fig. 6).

In order to evaluate the relationship between teleconnection indices phases of NAO, BWA and AMO with strong blocking episodes, we isolated the extreme values that correspond to months with standardized blocking occurrences larger than 2. In total, for the entire period analyzed, we

found 61 months meeting this criterion (Table 4). For the large majority, these months correspond to negative NAO ( $88.5 \%$ of months) and positive BWA ( $83.5 \%$ of months) anomalies. Hence, more frequent and stronger blocking events occur during phases of negative $\mathrm{NAO}$ and positive BWA, in agreement with results from Scherrer et al. (2006) and Rimbu et al. (2014). In the study by Rimbu et al. (2014), high blocking activity over Greenland-Iceland and northern Scandinavian regions is also associated with the negative NAO.

Figure 7 shows the distribution over years of number of North Atlantic blocked days for positive and negative phases of NAO, BWA and AMO. The number of blocked days is much larger during phases of negative NAO and positive BWA than during phases of positive NAO and negative BWA. The mean duration of blocking events (not shown) appears to be also sensitive to the NAO and BWA patterns. For example, blocking events persist more than 13 days (on average) when the NAO is negative. Conversely, they persist for only 8 days during the positive phase of NAO. These results are consistent with those obtained by Shabbar et al. (2001), who found that $67 \%$ more winter blocking days occur during negative phases of the NAO than during positive phases. In the case of AMO, there is no clear difference between the negative and positive phases of this index and the features of extreme values of blocked days (Table 4).

The CCM method was applied to analyze the causal relationships between NAO, BWA and AMO versus the North Atlantic blocking occurrences. Figure 8 presents the variation in the cross-map skill (rho) as a function of length of library (L). The causality is confirmed when rho substantially increases and converges with the increasing $\mathrm{L}$. The black line represents the causal skill of teleconnections versus the blocking occurrence relationship, while the red line represents the causal skill of blocking occurrence versus the teleconnections relationship. These lines correspond to average values of rho over 100 randomly sampled libraries. The dashed lines represent the confidence interval of rho (average \pm one standard deviations over 100 randomly sampled libraries). As shown in Fig. 8, rho values increased with $\mathrm{L}$ (e.g., the value of rho increased from 0.04 , smallest possible library size, to 0.38 , maximum possible library size) in the case of testing causality between NAO and blocking

Table 4 Distribution of teleconnection phases (i.e., positive or negative anomalies) for NAO, BWA and AMO during extreme month in terms of blocking occurrence (i.e., month where standardized anomalies of blocking occurrence is superior to 2)

\begin{tabular}{lll}
\hline & Positive & Negative \\
\hline NAO & $7(11.5 \%)$ & $54(88.5 \%)$ \\
BWA & $51(83.5 \%)$ & $10(16.5 \%)$ \\
AMO & $28(46 \%)$ & $33(54 \%)$ \\
\hline
\end{tabular}

For the 1901-2010 time period, a total of 61 months were found as extreme in terms of blocking occurrence 
Fig. 7 Distribution of the number of blocked days over years in the Atlantic sector with respect to the climate indices phases (NAO, BWA and AMO from top to bottom panels, respectively) from 1901 to 2010
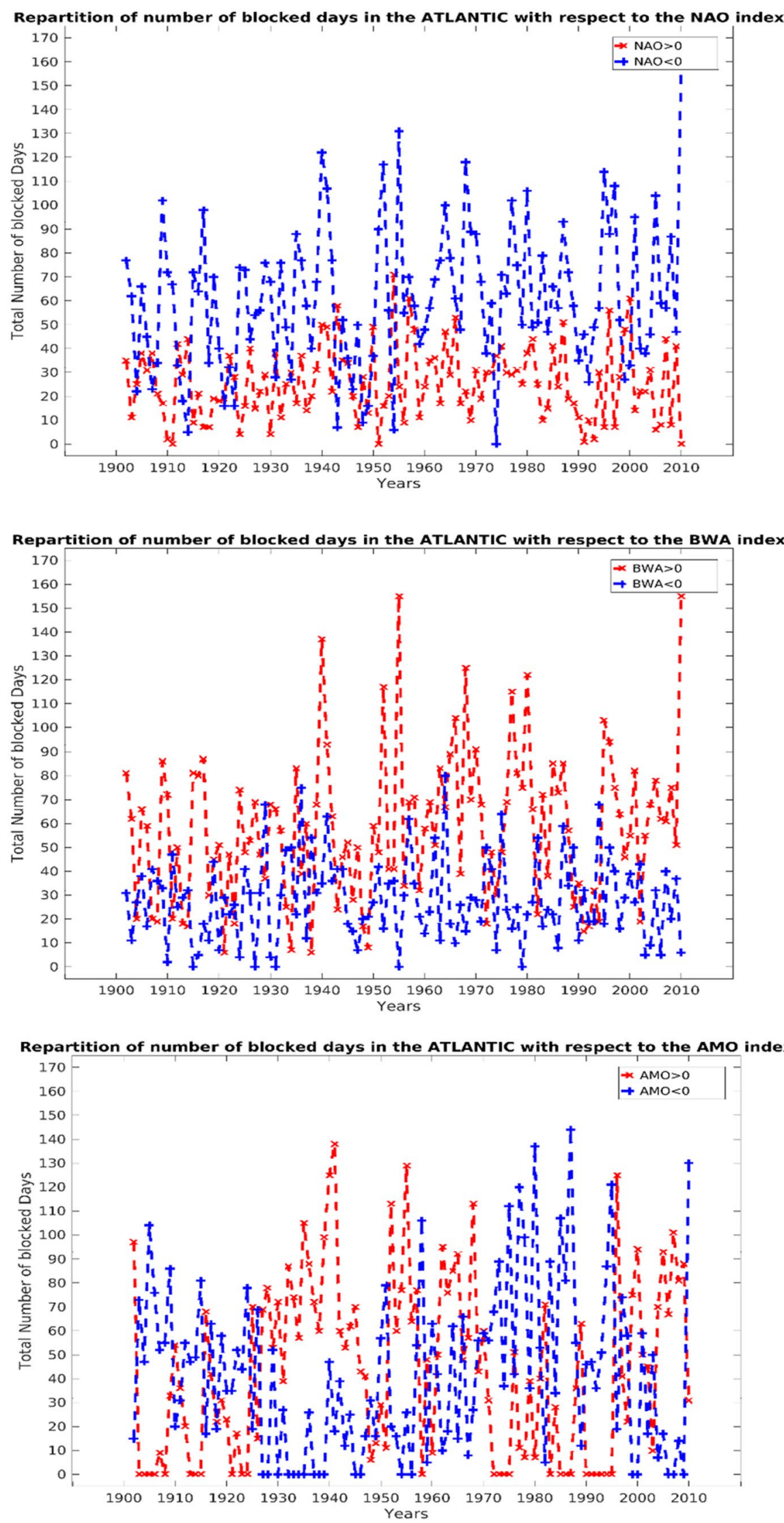

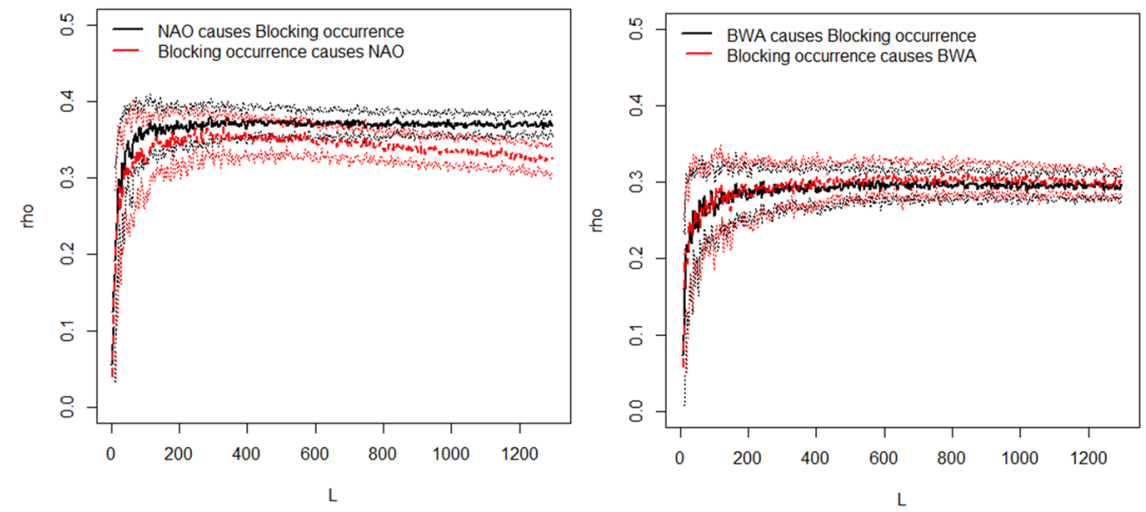

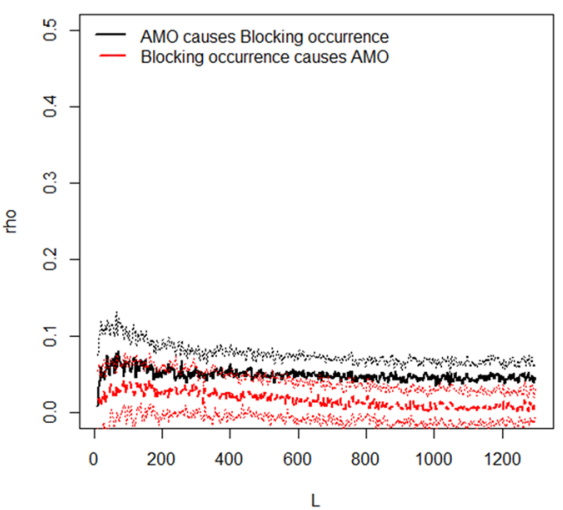

Fig. 8 Cross Mapping skill (computed using yearly data) as a function of length of library. Black lines represent the relationship between teleconnections causing blocking occurrence, and red lines represent the relationship between blocking occurrence causing tel- econnections. Dashed lines represent the confidence intervals of rho (rho \pm one standard deviation computed using 100 simulations or libraries) occurrence, and converged. This suggests a two-way statistically significant causal effect between blocking occurrence and both NAO and BWA, but not AMO (last panel of Fig. 8). For NAO, with the increase of $\mathrm{L}$, the red and black confidence intervals of rho values do not overlap, which means that the differences in rho values between the directions of causality depicted by the black and red lines are statistically significant. Therefore, the effect of NAO on blocking occurrence is statistically larger than the influence of blocking occurrence on NAO, which is not the case with BWA and AMO. The BWA index shows a clear two-way (equal) link with a similar confidence interval of rho in both cases (i.e., robust causality) and that is less scattered than the links for the NAO two-way relationships. Note that the causality signals between teleconnections indices and the remaining blocking characteristics (i.e., extension, duration and intensity) are presented in the online supplemental material (see Figures S8, S9 and S10). We note that the causality signals are generally less significant than those obtained with respect to blocking occurrences. Figure S8 also shows that the effect of teleconnection indices on blocking intensity is clearly larger than the effect of blocking intensity on teleconnection indices, especially in the case of BWA.

\section{Summary, conclusions and future works}

In this study, the relationships between atmospheric blocking and a set of climatic variables (MSLP, 500-hPa GZ, SAT, SST and SIC) and indices (NAO, AMO and BWA) reflecting both atmospheric and oceanic internal variability was examined using the coupled reanalysis CERA-20C dataset spanning from 1901 to 2010. Higher number and longerlasting $\mathrm{NH}$ blocking events were found using the extended period, coupled CERA-20C dataset than were reported in the literature using non-coupled reanalysis products for shorter periods. The number of NH blocking events varies seasonally, with maximum in winter-spring and minimum in summer-fall. Even if no significant change was found in the $\mathrm{NH}$ blocking frequencies over the 110-year period (1901-2010), blocking events became more intense and longer lasting across the time in some seasons and for some sectors. Over the North Atlantic, atmospheric blocking events are associated with a dipole of anomaly centers, with high pressure in the north and low pressure in the south leading to a shift of extratropical cyclone tracks toward the tropical Atlantic. The associated links between seasonal-mean near surface air temperature and North Atlantic blocking days are stronger in winter, and to a lesser extent in spring and fall, with cold anomalies in northern Europe and the United States, and warm anomalies over Greenland and northeastern Canada. These patterns are associated with higher than normal SSTs over the subpolar and tropical regions of the North Atlantic, and cooler conditions over western boundary current of the North Atlantic near the United States coasts, along with a reduction in the seasonal sea-ice concentration over the marginal seas of Canada, especially in winter and fall.

A high correlation was found between North Atlantic blocking occurrence and BWA and NAO indices. Moreover, the number of blocked days is sensitive to BWA and NAO, an increased number of blocked days being associated with negative phases of NAO and positive phases of BWA. Moreover, in some situations, the BWA pattern provides clearer links with the blocking occurrence in the North Atlantic, something that is not always captured by the NAO alone. In terms of causality, two-way significant effects appear between both NAO and BWA indices and blocking occurrence. Causal links with blocking occurrence over the North Atlantic are less obvious and more tenuous for the AMO than for the NAO and BWA indices. However, the variability 
of atmospheric blocking from interannual to multidecadal scales shows substantial correlation with the SSTs, albeit with significant changes in the Atlantic Ocean circulation led by wind-stress curl and air-sea heat exchange (not analyzed here), as noted by Häkkinen et al. (2011). The warm-ocean/ cold-land anomaly pattern shown in our correlation maps (Figs. 3, 4) could be linked to a dynamical environment favorable for blocking occurrence (e.g., Barriopedro et al. 2010; Croci-Maspoli and Davies 2009; Shabbar et al. 2001). Therefore, as demonstrated in Diao et al. (2006) for the NH, independent blocking events are frequent, whereas synchronous blocking occurrences are rare, indicating that the blocking events are local phenomena, with regional to extraregional interrelation. Hence, the North Atlantic SSTs or AMO anomalies can potentially trigger blocking occurrence along with atmospheric dynamic influences (see Rimbu et al. 2014; Nakamura and Huang 2018), as shown here with the clear links between the BWA positive phase and the blocking occurrence, duration and intensity (see Figures S8 and S9 in the online supplemental material).

Our study cannot separate clearly cause and effect between high blocking activity and warm ocean surface and other atmospheric dynamical features or forcing factors. It is, however, clear that mid-latitude atmosphere-ocean interactions, especially over the North Atlantic, support and involve increased persistence of atmospheric anomalies as blocking occurrences. Such interactions strongly vary seasonally and spatially from year to year and at the multidecadal scale. As proposed by Rimbu et al. (2014), multivariate analyses of blocking indicators will give additional information about blocking and related climate phenomena variability and predictability. Hence, future work should include a multi-variate analysis to clarify the relationships and causal effects.

Furthermore, the complete life cycle of blocking occurrences, duration, intensity and extent vary between models and reanalysis (see Hartung et al. 2017). Their representation in climate models depend upon physical parameterization, atmospheric resolution both vertical and horizontal, the realism of SSTs in a model whether prescribed or coupled (see Scaife et al. 2011), and complexity of atmosphere-ocean interaction in climate models, with or without coupling between the atmosphere and the ocean (see Davini and D'Andrea 2016; Masato et al. 2013). This is particularly the case for winter blocking events over the North Atlantic, as these are particularly sensitive to physical parameterizations, both in atmosphere-only and coupled simulations (see Hartung et al. 2017). Further work is needed to evaluate the blocking characteristics over the North Atlantic area using a regional climate model, with higher spatial and temporal resolution than the global climate model, including the CERA20C reanalysis product used here. This will allow evaluating the effect of increasing resolution on blocking occurrence, intensity and duration, and their links with climate indices and variables over the North Atlantic and adjacent continental land masses. Moreover, the use of the new global ERA-5 (Hersbach et al. 2020) dataset at around 25-km of horizontal resolution (Copernicus Climate Change Service 2017) to compute the blocking characteristics and to drive the regional climate model over the recent decades are also planned. This will permit comparison with the CERA-20C products used here using higher resolution reanalysis data.

In our study, one member (member 0 ) of the ten available members for CERA-20C was used. In a future study, we plan to do a robustness analysis by repeating the same analysis on each of the ten available members, and then explore the possible full range of variability from all blocking characteristics. As the blocking characteristics and their links with teleconnection indices are prone to have substantial effects on surface atmospheric variables and their seasonal anomalies over the North America and European landmasses, some simulations are underway over the North Atlantic (also covering eastern North America and Western Europe). This will be done using our regional climate model (developed at the ESCER center), driven by two global climate models under various future climate conditions. These will allow evaluating future trends in blocking activities over the North Atlantic and their influences on natural (climate) risks, such as cold/warm spells and with the combined potential effect of drought or wet sequences on either extensive forest fires or flood events. Also, further studies need to be done, as the one recently made by Hwang et al. (2020) over the North Pacific, to fully explain key patterns of blocking events and to more precisely understand the role of transient eddies or poleward shift in the storm tracks in the blocking formation. This is crucial to improve our current knowledge (i.e., physical processes) about the effects on regional climate anomalies from the blocking characteristics and its background.

Furthermore, we used the method of Barriopedro et al. (2006) to detect blocking events and to compute the blocking event characteristics. As mentioned in previous studies, different blocking methods do not necessarily give consistent statistics. Therefore, future work should include the calculation of blocking events in the CERA-20C reanalysis using other currently available blocking algorithms and identify robust statistics between methods. It would also be interesting to make a sensitivity analysis showing the dependence of results to free parameters used in the blocking detection algorithm, including duration and amplitude thresholds.

Supplementary Information The online version contains supplementary material available at https://doi.org/10.1007/s00382-020-05583-x.

Acknowledgements Financial support for this study was provided by the Fonds de recherche du Québec (FRQ) through the ClimHuNor project, and by the Natural Sciences and Engineering Research Council 
of Canada from the individual grant of Philippe Gachon. The CERA20C data sets used in this study were downloaded from the site https ://www.ecmwf.int/en/forecasts/datasets/reanalysis-datasets/cera-20c. The researchers involved in compiling these data products are gratefully acknowledged. We acknowledge the team of the ESCER centre, namely Guillaume Dueymes, François Roberge and Katja Winger for their help in the management and in the preparation of climate data.

Open Access This article is licensed under a Creative Commons Attribution 4.0 International License, which permits use, sharing, adaptation, distribution and reproduction in any medium or format, as long as you give appropriate credit to the original author(s) and the source, provide a link to the Creative Commons licence, and indicate if changes were made. The images or other third party material in this article are included in the article's Creative Commons licence, unless indicated otherwise in a credit line to the material. If material is not included in the article's Creative Commons licence and your intended use is not permitted by statutory regulation or exceeds the permitted use, you will need to obtain permission directly from the copyright holder. To view a copy of this licence, visit http://creativecommons.org/licenses/by/4.0/.

\section{References}

Barnes EA, Screen JA (2015) The impact of Arctic warming on the midlatitude jet-stream: Can it? Has it? Will it? Wiley Interdiscip Rev Clim Change 6(3):277-286. https://onlinelibrary.wiley.com/ doi/abs/10.1002/wcc.337

Barnes EA, Slingo J, Woollings T (2012) A methodology for the comparison of blocking climatologies across indices, models and climate scenarios. Clim Dyn 38(11-12):2467-2481

Barnes EA, Dunn-Sigouin E, Masato G, Woollings T (2014) Exploring recent trends in Northern Hemisphere blocking. Geophys Res Lett 41(2):638-644. https://agupubs.onlinelibrary.wiley.com/doi/ abs/10.1002/2013GL058745

Barnston AG, Livezey RE (1987) Classification, seasonality and persistence of low-frequency atmospheric circulation patterns. Mon Weather Rev 115(6):1083-1126. https://journals.ametsoc.org/ doi/abs/10.1175/1520-0493\%281987\%29115\%3C1083\%3ACSA POL\%3E2.0.CO\%3B2

Barriopedro D, García-Herrera R, Lupo AR, Hernández E (2006) A climatology of northern hemisphere blocking. J Clim 19(6):10421063. https://journals.ametsoc.org/doi/abs/10.1175/JCLI3678.1

Barriopedro D, García-Herrera R, González-Rouco JF, Trigo RM (2010) Application of blocking diagnosis methods to general circulation models part II: model simulations. Clim Dyn 35(7):1393-1409. https://doi.org/10.1007/s00382-010-0766-6

Benedict JJ, Lee S, Feldstein SB (2004) Synoptic view of the North Atlantic oscillation. J Atmos Sci 61(2):121-144. https://journ als.ametsoc.org/doi/abs/10.1175/1520-0469\%282004\%29061 $\% 3 \mathrm{C} 0121 \% 3 \mathrm{ASVOTNA} \% 3 \mathrm{E} 2.0 . \mathrm{CO} \% 3 \mathrm{~B} 2$

Black E, Blackburn M, Harrison G, Hoskins B, Methven J (2004) Factors contributing to the summer 2003 European heatwave. Weather 59(8):217-223. https://rmets.onlinelibrary.wiley.com/ doi/abs/10.1256/wea.74.04

Brunner L, Steiner AK (2017) A global perspective on atmospheric blocking using GPS radio occultation-one decade of observations. Atmos Meas Tech 10(12):4727-4745. https://www.atmos -meas-tech.net/10/4727/2017/

Carrera ML, Higgins RW, Kousky VE (2004) Downstream weather impacts associated with atmospheric blocking over the Northeast Pacific. J Clim 17(24):4823-4839. https://journals.ametsoc.org/ doi/abs/10.1175/JCLI-3237.1
Cassou C (2008) Intraseasonal interaction between the Madden-Julian Oscillation and the North Atlantic Oscillation. Nature 455:523. https://doi.org/10.1038/nature07286

Cattiaux J, Douville H, Ribes A, Chauvin F, Plante C (2013) Towards a better understanding of changes in wintertime cold extremes over Europe: a pilot study with CNRM and IPSL atmospheric models. Clim Dyn 40(9-10):2433-2445

Cellitti MP, Walsh JE, Rauber RM, Portis DH (2006) Extreme cold air outbreaks over the United States, the polar vortex, and the largescale circulation. J Geophys Res Atmos 111(D2). https://agupu bs.onlinelibrary.wiley.com/doi/abs/10.1029/2005JD006273

Colucci SJ, Alberta TL (1996) Planetary-scale climatology of explosive cyclogenesis and blocking. Mon Weather Rev 124(11):2509_ 2520. https://journals.ametsoc.org/doi/abs/10.1175/15200493\%281996\%29124\%3C2509\%3APSCOEC\%3E2.0.CO\%3B2

Copernicus Climate Change Service (C3S) (2017) ERA5: Fifth generation of ECMWF atmospheric reanalyses of the global climate. Copernicus Climate Change Service Climate Data Store (CDS). https://cds.climate.copernicus.eu/cdsapp\#!/home

Coulibaly P, Anctil F, Rasmussen P, Bobée B (2000) A recurrent neural networks approach using indices of low-frequency climatic variability to forecast regional annual runoff. Hydrol Process 14(15):2755-2777. https://onlinelibrary.wiley.com/doi/ abs/10.1002/1099-1085\%2820001030\%2914\%3A15\%3C275 5\%3A\%3AAID-HYP90\%3E3.0.CO\%3B2-9

Croci-Maspoli M, Davies HC (2009) Key dynamical features of the 2005/06 European Winter. Mon Weather Rev 137(2):664-678. https://journals.ametsoc.org/doi/abs/10.1175/2008MWR253 3.1

Croci-Maspoli M, Schwierz C, Davies HC (2007) Atmospheric blocking: space-time links to the NAO and PNA. Clim Dyn 29:713-725. https://doi.org/10.1007/s00382-007-0259-4

Davini P, D'Andrea F (2016) Northern hemisphere atmospheric blocking representation in global climate models: Twenty years of improvements? J Clim 29(24):8823-8840. https://journals. ametsoc.org/doi/abs/10.1175/JCLI-D-16-0242.1

Davini P, Cagnazzo C, Anstey J (2014) A blocking view of the stratosphere-troposphere coupling. J Geophys Res Atmos 119(19):11100-111115

Diao Y, Li J, Luo D (2006) A new blocking index and its application: blocking action in the Northern hemisphere. J Clim 19(19):4819-4839. https://journals.ametsoc.org/doi/ abs/10.1175/JCLI3886.1

Dole RM, Gordon ND (1983) Persistent anomalies of the extratropical Northern Hemisphere wintertime circulation: geographical distribution and regional persistence characteristics. Mon Weather Rev 111(8):1567-1586

Dole R, Hoerling M, Perlwitz J, Eischeid J, Pegion P, Zhang T et al (2011) Was there a basis for anticipating the 2010 Russian heat wave? Geophys Res Lett 38:L06702. https://doi. org/10.1029/2010GL046582. https://agupubs.onlinelibrary.wiley .com/doi/abs/10.1029/2010GL046582

Douglas E, Vogel R, Kroll C (2000) Trends in floods and low flows in the United States: impact of spatial correlation. J Hydrol 240(1-2):90-105

Enfield DB, Mestas-Nuñez AM, Trimble PJ (2001) The Atlantic Multidecadal oscillation and its relation to rainfall and river flows in the continental US. Geophys Res Lett 28(10):2077-2080. https:// agupubs.onlinelibrary.wiley.com/doi/abs/10.1029/2000GL0127 45

Fei H, Faxiu Z, Xiaodan Q (2002) Interannual and decadal variability of the north pacific blocking and its relationship to SST, teleconnection and storm tracks. Adv Atmos Sci 19(5):807-820. https:// doi.org/10.1007/s00376-002-0046-4

Feldstein SB (2000) The timescale, power spectra, and climate noise properties of teleconnection patterns. J Clim 13(24):4430-4440. 
https://journals.ametsoc.org/doi/abs/10.1175/1520-0442\%28200 0\%29013\%3C4430\%3ATTPSAC\%3E2.0.CO\%3B2

Feng S, Hu Q (2008) How the North Atlantic Multidecadal Oscillation may have influenced the Indian summer monsoon during the past two millennia. Geophys Res Lett 35:L01707. https://doi. org/10.1029/2007GL032484. https://agupubs.onlinelibrary.wiley .com/doi/abs/10.1029/2007GL032484

Folland CK, Palmer TN, Parker DE (1986) Sahel rainfall and worldwide sea temperatures, 1901-85. Nature 320(6063):602-607. https://doi.org/10.1038/320602a0

Folland CK, Colman AW, Rowell DP, Davey MK (2001) Predictability of Northeast Brazil Rainfall and Real-Time Forecast Skill, 1987-98. J Clim 14(9):1937-1958. https://journals.ametsoc.org/ doi/abs/10.1175/1520-0442\%282001\%29014\%3C1937\%3APON BRA\%3E2.0.CO\%3B2

Francis J, Skific N (2015) Evidence linking rapid Arctic warming to mid-latitude weather patterns. Philos Trans R Soc A Math Phys Eng Sci 373(2045):20140170. https://royalsocietypublishing.org/ doi/abs/10.1098/rsta.2014.0170

Francis JA, Vavrus SJ (2012) Evidence linking Arctic amplification to extreme weather in mid-latitudes. Geophys Res Lett 39:L06801. https://doi.org/10.1029/2012GL051000

García-Herrera R, Barriopedro D (2006) Northern Hemisphere snow cover and atmospheric blocking variability. J Geophys Res Atmos. https://agupubs.onlinelibrary.wiley.com/doi/ abs/10.1029/2005JD006975

Granger CW (1969) Investigating causal relations by econometric models and cross-spectral methods. Econom J Econom Soc 37(3):424-438

Grotjahn R, Black R, Leung R, Wehner MF, Barlow M, Bosilovich $M$ et al (2016) North American extreme temperature events and related large scale meteorological patterns: a review of statistical methods, dynamics, modeling, and trends. Clim Dyn 46(3):1151-1184. https://doi.org/10.1007/s00382-015-2638-6

Guirguis K, Gershunov A, Schwartz R, Bennett S (2011) Recent warm and cold daily winter temperature extremes in the Northern Hemisphere. Geophys Res Lett 38(17):L17701. https://doi. org/10.1029/2011GL048762

Hahn LC et al (2020) Importance of orography for Greenland Cloud and melt response to atmospheric blocking. J Clim 33(10):4187-4206

Häkkinen S, Rhines PB, Worthen DL (2011) Atmospheric blocking and Atlantic Multidecadal ocean variability. Science 334(6056):655659. https://science.sciencemag.org/content/sci/334/6056/655. full.pdf

Hartung K, Svensson G, Kjellström E (2017) ResolOution, physics and atmosphere-ocean interaction-how do they influence climate model representation of Euro-Atlantic atmospheric blocking? Tellus A Dyn Meteorol Oceanogr 69(1):1406252. https://doi. org/10.1080/16000870.2017.1406252

Hersbach H, Bell B, Berrisford P et al (2020) The ERA5 global reanalysis. Q J R Meteorol Soc 146:1999-2049. https://doi. org/10.1002/qj.3803

Hurrel JW, Van Loon H (1997) Decadal variations in climate associated with the North Atlantic oscillation. Clim Change 36(3):301-326. https://doi.org/10.1023/A:1005314315270

Hurrell JW (1995) Decadal trends in the North Atlantic Oscillation: regional temperatures and precipitation. Science 269(5224):676-679

Hwang J, Martineau P, Son S, Miyasaka T, Nakamura H (2020) The role of transient Eddies in North Pacific blocking formation and its seasonality. J Atmos Sci 77:2453-2470. https://doi. org/10.1175/JAS-D-20-0011.1

Ionita M, Scholz P, Lohmann G, Dima M, Prange M (2016) Linkages between atmospheric blocking, sea ice export through Fram
Strait and the Atlantic Meridional overturning circulation. Sci Rep 6:32881. https://doi.org/10.1038/srep32881

IPCC (2013) Climate Change 2013: The Physical Science Basis. In: Stocker TF, Qin D, Plattner G-K, Tignor M, Allen SK, Boschung J, Nauels A, Xia Y, Bex V, Midgley PM (eds) Contribution of Working Group I to the Fifth Assessment Report of the Intergovernmental Panel on Climate Change. Cambridge University Press, Cambridge, New York

Kalnay E, Kanamitsu M, Kistler R, Collins W, Deaven D, Gandin L, Iredell M, Saha S, White G, Woollen J, Zhu Y, Chelliah M, Ebisuzaki W, Higgins W, Janowiak J, Mo KC, Ropelewski C, Wang J, Leetmaa A, Reynolds R, Jenne R, Joseph D (1996) The NCEP/NCAR 40-year reanalysis project. Bull Am Meteor Soc $77: 437-471$

Kendall MG (1948) Rank correlation methods. Griffin, Oxford

Khaliq MN, Ouarda TBMJ, Gachon P, Sushama L (2008) Temporal evolution of low-flow regimes in Canadian rivers. Water Resour Res 44(8):W08436. https://doi.org/10.1029/2007WR006132

Khaliq MN, Ouarda TBMJ, Gachon P, Sushama L, St-Hilaire A (2009) Identification of hydrological trends in the presence of serial and cross correlations: a review of selected methods and their application to annual flow regimes of Canadian rivers. J Hydrol 368(1):117-130. http://www.sciencedirect.com/science/article/ pii/S0022169409000651

Knight JR, Folland CK, Scaife AA (2006) Climate impacts of the Atlantic multidecadal oscillation. Geophys Res Lett 33(17):L17706. https://doi.org/10.1029/2006GL026242

Knox JL, Hay JE (1985) Blocking signatures in the northern hemisphere: frequency distribution and interpretation. J Climatol 5(1): $1-16$

Kulkarni A, von Storch H (1995) Monte Carlo experiments on the effect of serial correlation on the Mann-Kendall test of trend. Meteorol Z 4(2):82-85

Kwon YO et al (2020) Impact of multidecadal variability in Atlantic SST on Winter atmospheric blocking. J Clim. https://doi. org/10.1175/JCLI-D-19-0324.1. https://rmets.onlinelibrary.wiley .com/doi/abs/10.1002/joc.3370050102

Laloyaux P, Balmaseda M, Dee D, Mogensen K, Janssen P (2016) A coupled data assimilation system for climate reanalysis. Q J R Meteorol Soc 142(694):65-78. https://rmets.onlinelibrary.wiley .com/doi/abs/10.1002/qj.2629

Laloyaux P, de Boisseson E, Balmaseda M, Bidlot J-R, Broennimann S, Buizza R et al (2018) CERA-20C: a coupled reanalysis of the Twentieth Century. J Adv Model Earth Syst 10(5):1172-1195. https://agupubs.onlinelibrary.wiley.com/doi/abs/10.1029/2018M S001273

Lejenäs H, Økland H (1983) Characteristics of Northern Hemisphere blocking as determined from a long time series of observational data. Tellus A 35(5):350-362

Lupo AR, Mokhov II, Akperov MG, Chernokulsky AV, Athar H (2012) A dynamic analysis of the role of the planetary- and synoptic-scale in the summer of 2010 blocking episodes over the European Part of Russia. Adv Meteorol 2012:11. https://doi. org/10.1155/2012/584257

Lupo AR, Jensen AD, Mokhov II, Timazhev AV, Eichler T, Efe B (2019) Changes in global blocking character during the most recent decades. Atmosphere 10:19

Madden RA, Julian PR (1994) Observations of the 40-50 day tropical oscillation: a review. Mon Weather Rev 122:814-837

Mann ME, Rahmstorf S, Kornhuber K, Steinman BA, Miller SK, Coumou D (2017) Influence of anthropogenic climate change on planetary wave resonance and extreme weather events. Sci Rep 7:45242. https://doi.org/10.1038/srep45242

Mann HB (1945) Nonparametric tests against trend. Econom J Econom Soc 13(3):245-259 
Masato G, Hoskins BJ, Woollings T (2013) Winter and summer Northern Hemisphere blocking in CMIP5 models. J Clim 26(18):7044-7059. https://journals.ametsoc.org/doi/abs/10.1175/ JCLI-D-12-00466.1

Messori G, Caballero R, Gaetani M (2016) On cold spells in North America and storminess in Western Europe. Geophys Res Lett 43(12):6620-6628. https://agupubs.onlinelibrary.wiley.com/doi/ abs/10.1002/2016GL069392

Mitchell DM, Gray LJ, Anstey J, Baldwin MP, Charlton-Perez AJ (2013) The influence of stratospheric vortex displacements and splits on surface climate. J Clim 26(8):2668-2682

Mokhov II, Akperov MG, Prokofyeva MA, Timazhev AV, Lupo AR, Le Treut H (2012) Blockings in the Northern Hemisphere and Euro-Atlantic region: Estimates of changes from reanalyses data and model simulations. Doklady 449:430-433

Moore GWK, Renfrew IA, Pickart RS (2013) Multidecadal mobility of the North Atlantic Oscillation. J Clim 26(8):2453-2466. https:// journals.ametsoc.org/doi/abs/10.1175/JCLI-D-12-00023.1

Mullen SL (1989) Model experiments on the impact of Pacific sea surface temperature anomalies on blocking frequency. J Clim 2(9):997-1013. https://doi.org/10.1175/15200442(1989)002\%3c0997:MEOTIO\%3e2.0.CO;2

Nakamura N, Huang CSY (2018) Atmospheric blocking as a traffic jam in the jet stream. Science 361(6397):42-47. https://science.scien cemag.org/content/sci/361/6397/42.full.pdf

O'Reilly CH, Minobe S, Kuwano-Yoshida A (2016) The influence of the Gulf Stream on wintertime European blocking. Clim Dyn 47(5):1545-1567. https://doi.org/10.1007/s00382-015-2919-0

Parsons S, Renwick JA, McDonald AJ (2016) An assessment of future southern hemisphere blocking using CMIP5 projections from four GCMs. J Clim 29(21):7599-7611. https://journals.amets oc.org/doi/abs/10.1175/JCLI-D-15-0754.1

Pelly JL, Hoskins BJ (2003) A new perspective on blocking. J Atmos Sci 60(5):743-755

Pfahl S, Schwierz C, Croci-Maspoli M, Grams CM, Wernli H (2015) Importance of latent heat release in ascending air streams for atmospheric blocking. Nat Geosci 8:610. https://doi.org/10.1038/ ngeo 2487

Photiadou C, Jones MR, Keellings D, Dewes CF (2014) Modeling European hot spells using extreme value analysis. Clim Res 58(3):193-207

Poan ED, Gachon P, Laprise R, Aider R, Dueymes G (2018) Investigating added value of regional climate modeling in North American winter storm tracks simulations. Clim Dyn 50(5-6):1799-1818. https://doi.org/10.1007/s00382-017-3723-9

Poli P, Hersbach H, Dee DP, Berrisford P, Simmons AJ, Vitart F et al (2016) ERA-20C: an atmospheric reanalysis of the Twentieth Century. J Clim 29(11):4083-4097. https://journals.ametsoc.org/ doi/abs/10.1175/JCLI-D-15-0556.1

Rex DF (1950) Blocking action in the middle troposphere and its effect upon regional climate. Tellus 2(3):196-211. https://onlinelibrary. wiley.com/doi/abs/10.1111/j.2153-3490.1950.tb00331.x

Rimbu N, Lohmann G (2011) Winter and summer blocking variability in the North Atlantic region-evidence from long-term observational and proxy data from southwestern Greenland. Clim Past 7(2):543-555. https://www.clim-past.net/7/543/2011/

Rimbu N, Lohmann G, Ionita M (2014) Interannual to multidecadal Euro-Atlantic blocking variability during winter and its relationship with extreme low temperatures in Europe. J Geophys Res Atmos 119(24):13,621-13,636. https://agupubs.onlinelibrary. wiley.com/doi/abs/10.1002/2014JD021983

Robertson AW, Mechoso CR, Kim Y-J (2000) The influence of Atlantic Sea Surface temperature anomalies on the North Atlantic oscillation. J Clim 13(1):122-138. https://journals.ametsoc.org/doi/ abs/10.1175/1520-0442\%282000\%29013\%3C0122\%3ATIO ASS\%3E2.0.CO\%3B2
Rodwell MJ, Rowell DP, Folland CK (1999) Oceanic forcing of the wintertime North Atlantic Oscillation and European climate. Nature 398(6725):320-323. https://doi.org/10.1038/18648

Rohrer M, Brönnimann S, Martius O, Raible CC, Wild M (2019) Decadal variations of blocking and storm tracks in centennial reanalyses. Tellus A Dyn Meteorol Oceanogr 71(1):1586236. https ://doi.org/10.1080/16000870.2019.1586236

Rohrer M, Martius O, Raible CC, Brönnimann S (2020) Sensitivity of blocks and cyclones in ERA5 to spatial resolution and definition. Geophys Res Lett 47:e2019GL085582. https://doi. org/10.1029/2019GL085582

Sampe T, Nakamura H, Goto A, Ohfuchi W (2010) Significance of a Midlatitude SST frontal zone in the formation of a Storm Track and an Eddy-Driven Westerly Jet. J Clim 23(7):1793-1814. https ://journals.ametsoc.org/doi/abs/10.1175/2009JCLI3163.1

Scaife AA, Copsey D, Gordon C, Harris C, Hinton T, Keeley S, O’Neill A, Roberts M, Williams K (2011) Improved Atlantic winter blocking in a climate model. Geophys Res Lett 38:L23703. https ://doi.org/10.1029/2011GL049573

Scherrer SC, Croci-Maspoli M, Schwierz C, Appenzeller C (2006) Two-dimensional indices of atmospheric blocking and their statistical relationship with winter climate patterns in the EuroAtlantic region. Int J Climatol 26(2):233-249. https://rmets.onlin elibrary.wiley.com/doi/abs/10.1002/joc. 1250

Schiff SJ, So P, Chang T, Burke RE, Sauer T (1996) Detecting dynamical interdependence and generalized synchrony through mutual prediction in a neural ensemble. Phys Rev E 54(6):6708

Schwierz C, Croci-Maspoli M, Davies HC (2004) Perspicacious indicators of atmospheric blocking. Geophys Res Lett 31(6):L06125. https://doi.org/10.1029/2003GL019341

Sen PK (1968) Estimates of the regression coefficient based on Kendall's tau. J Am Stat Assoc 63:1379-1389

Shabbar A, Higuchi K, Skinner W, Knox JL (1997) The association between the BWA index and winter surface temperature variability over eastern Canada and west Greenland. Int J Climatol 17(11):1195-1210. https://rmets.onlinelibrary. wiley.com/doi/abs/10.1002/\%28SICI\%291097-0088\%28199 $709 \% 2917 \% 3$ A $11 \% 3$ C $1195 \% 3$ A \% 3 A A ID - J OC 19 $0 \% 3 \mathrm{E} 3.0 . \mathrm{CO} \% 3 \mathrm{~B} 2-\mathrm{U}$

Shabbar A, Huang J, Higuchi K (2001) The relationship between the wintertime north Atlantic oscillation and blocking episodes in the north Atlantic. Int J Climatol 21(3):355-369. https://rmets .onlinelibrary.wiley.com/doi/abs/10.1002/joc.612

Shutts GJ (1983) The propagation of eddies in diffluent jetstreams: Eddy vorticity forcing of 'blocking' flow fields. Q J R Meteorol Soc 109(462):737-761. https://rmets.onlinelibrary.wiley.com/ doi/abs/10.1002/qj.49710946204

Sillmann J, Croci-Maspoli M (2009) Present and future atmospheric blocking and its impact on European mean and extreme climate. Geophys Res Lett 36(10):L10702. https://doi.org/10.1029/2009G L038259

Sillmann J, Croci-Maspoli M, Kallache M, Katz RW (2011) Extreme Cold Winter temperatures in Europe under the influence of North Atlantic Atmospheric blocking. J Clim 24(22):5899-5913. https ://journals.ametsoc.org/doi/abs/10.1175/2011JCLI4075.1

Slivinski LC, Compo GP, Whitaker JS et al (2019) Towards a more reliable historical reanalysis: improvements for version 3 of the Twentieth Century Reanalysis system. Q J R Meteorol Soc 145:2876-2908. https://doi.org/10.1002/qj.3598

Spearman C (1904) The proof and measurement of association between two things. Am J Psychol 15(1):72-101

Stankūnavičius G, Basharin D, Skorupskas R, Vivaldo G (2017) EuroAtlantic blocking events and their impact on surface air temperature and precipitation over the European region in the 20th century. Clim Res 71(3):203-218. https://www.int-res.com/abstr acts/cr/v71/n3/p203-218/ 
Stocker T (2014) Climate change 2013: the physical science basis: Working Group I contribution to the Fifth assessment report of the Intergovernmental Panel on Climate Change. Cambridge University Press, Cambridge

Sugihara G, May R, Ye H, Hsieh CH, Deyle E, Fogarty M, Munch S (2012) Detecting causality in complex ecosystems. Science 338(6106):496-500

Takens F (1981) Detecting strange attractors in turbulence. In: Rand D, Young LS (eds) Dynamical Systems and turbulence, Warwick 1980. Lecture notes in mathematics, vol 898. Springer, Berlin, Heidelberg. https://doi.org/10.1007/BFb0091924

Tibaldi S, Molteni F (1990) On the operational predictability of blocking. Tellus A 42(3):343-365. https://onlinelibrary.wiley.com/doi/ abs/10.1034/j.1600-0870.1990.t01-2-00003.x

Treidl RA, Birch EC, Sajecki P (1981) Blocking action in the northern hemisphere: a climatological study. Atmos Ocean 19(1):1-23. https://doi.org/10.1080/07055900.1981.9649096

Trenberth KF, Mo KC (1985) Blocking in the southern hemisphere. Mon Weather Rev 113(1):3-21. https://journals.ametsoc.org/ doi/abs/10.1175/1520-0493\%281985\%29113\%3C0003\%3ABIT $\mathrm{SH} \% 3 \mathrm{E} 2.0 . \mathrm{CO} \% 3 \mathrm{~B} 2$

Trenberth KE, Shea DJ (2006) Atlantic hurricanes and natural variability in 2005. Geophys Res Lett 33(12):L12704. https://doi. org/10.1029/2006GL026894

Trigo RM, Osborn TJ, Corte-Real JM (2002) The North Atlantic Oscillation influence on Europe: climate impacts and associated physical mechanisms. Clim Res 20:9-17

Trigo RM, Trigo IF, DaCamara CC, Osborn TJ (2004) Climate impact of the European winter blocking episodes from the NCEP/NCAR Reanalyses. Clim Dyn 23(1):17-28. https://doi.org/10.1007/ s00382-004-0410-4

Tsonis AA, Deyle ER, May RM, Sugihara G, Swanson K, Verbeten JD, Wang G (2015) Dynamical evidence for causality between galactic cosmic rays and interannual variation in global temperature. Proc Natl Acad Sci 112(11):3253-3256. https://www.pnas.org/ content/pnas/112/11/3253.full.pdf

Tsou C-H, Smith PJ (1990) The role of synoptic/planetary-scale interactions during the development of a blocking anticyclone. Tellus A 42(1):174-193. https://onlinelibrary.wiley.com/doi/abs/10.10 34/j.1600-0870.1990.00015.x

Tyrlis E, Hoskins BJ (2008) Aspects of a northern hemisphere atmospheric blocking climatology. J Atmos Sci 65(5):1638-1652. https ://journals.ametsoc.org/doi/abs/10.1175/2007JAS2337.1

van Nes EH, Scheffer M, Brovkin V, Lenton TM, Ye H, Deyle E, Sugihara G (2015) Causal feedbacks in climate change. Nat Clim Change 5:445. https://doi.org/10.1038/nclimate2568

Venegas SA, Mysak LA (2000) Is there a dominant timescale of natural climate variability in the Arctic? J Clim 13(19):3412-3434. https://journals.ametsoc.org/doi/abs/10.1175/1520-0442\%28200 0\%29013\%3C3412\%3AITADTO\%3E2.0.CO\%3B2

von Storch H (1995) Misuses of statistical analysis in climate research. In: von Storch H, Navarra A (eds) Analysis of climate variability: applications of statistical techniques. Springer, Berlin, pp 11-26

Walsh JE, Phillips AS, Portis DH, Chapman WL (2001) Extreme cold outbreaks in the United States and Europe, 1948-99. J
Clim 14(12):2642-2658. https://journals.ametsoc.org/doi/ abs/10.1175/1520-0442\%282001\%29014\%3C2642\%3AECO ITU\%3E2.0.CO\%3B2

Wang C, Xie S-P, Carton JA (2004) A global survey of ocean-atmosphere interaction and climate variability. In: Wang $C$ et al (eds) Earth's climate: the ocean-atmosphere interaction, geophysical monograph series, vol 147. AGU, Washington, D.C., pp 1-19

Wang C, Liu H, Lee S-K (2010) The record-breaking cold temperatures during the winter of 2009/2010 in the Northern Hemisphere. Atmos Sci Lett 11(3):161-168. https://rmets.onlinelibrary.wiley .com/doi/abs/10.1002/asl.278

Wang Y, Yang J, Chen Y, De Maeyer P, Li Z, Duan W (2018) Detecting the causal effect of soil moisture on precipitation using convergent cross mapping. Sci Rep 8(1):12171. https://doi.org/10.1038/ s41598-018-30669-2

Whan K, Zwiers F, Sillmann J (2016) The influence of atmospheric blocking on extreme winter minimum temperatures in North America. J Clim 29(12):4361-4381. https://journals.ametsoc.org/ doi/abs/10.1175/JCLI-D-15-0493.1

Wheeler MC, Hendon HH (2004) An all-season real-time multivariate MJO Index: development of an index for monitoring and prediction. Mon Weather Rev 132(8):1917-1932. https://journ als.ametsoc.org/doi/abs/10.1175/1520-0493\%282004\%29132 \%3C1917\%3AAARMMI\%3E2.0.CO\%3B2

Wiedenmann JM, Lupo AR, Mokhov II, Tikhonova EA (2002) The climatology of blocking anticyclones for the Northern and Southern Hemispheres: block intensity as a diagnostic. J Clim 15(23):3459-3473. https://journals.ametsoc.org/doi/ abs/10.1175/1520-0442\%282002\%29015\%3C3459\%3ATCO BAF\%3E2.0.CO\%3B2

Woollings T, Hannachi A, Hoskins B (2010) Variability of the North Atlantic eddy-driven jet stream. Q J R Meteorol Soc 136(649):856-868. https://rmets.onlinelibrary.wiley.com/doi/ abs/10.1002/qj.625

Woollings T, Barriopedro D, Methven J, Son SW, Martius O, Harvey B, Seneviratne S (2018) Blocking and its response to climate change. Curr Clim Change Rep 4(3):287-300

Yang Y-M, Il AS, Wang B, Park JH (2020) A global-scale multidecadal variability driven by Atlantic multidecadal oscillation. Natl Sci Rev (1-8):2020. https://doi.org/10.1093/nsr/nwz216

Zhang C (2005) Madden-Julian oscillation. Rev Geophys 43:RG2003. https://doi.org/10.1029/2004RG000158

Zhang W, Luo D (2020) A nonlinear theory of atmospheric blocking: an application to Greenland blocking changes linked to Winter Arctic Sea Ice Loss. J Atmos Sci 77:723-751. https://doi. org/10.1175/JAS-D-19-0198.1

Zhang X, Harvey KD, Hogg WD, Yuzyk TR (2001) Trends in Canadian streamflow. Water Resour Res 37(4):987-998

Publisher's Note Springer Nature remains neutral with regard to jurisdictional claims in published maps and institutional affiliations. 